\title{
Characterization of 3-Dimensional Printing and Casting Materials for use in Magnetic Resonance Imaging Phantoms at 3 T
}

\author{
B. E. Yunker ${ }^{1,2}$, K. F. Stupic ${ }^{1}$, J. L. Wagner ${ }^{2}$, S. Huddle ${ }^{2}$, R. Shandas ${ }^{2}$, R. F. Weir ${ }^{2}$, \\ S. E. Russek ${ }^{1}$, and K. E. Keenan ${ }^{1}$
}

${ }^{1}$ Physical Measurement Laboratory, National Institute of Standards and Technology, Boulder, CO 80305, USA

${ }^{2}$ University of Colorado-Denver/Anschutz, Aurora, CO 80045, USA

bryan.yunker@ucdenver.edu karl.stupic@nist.gov

jennifer.wagner@ucdenver.edu stephen.huddle@ucdenver.edu

robin.shandas@ucdenver.edu

richard.weir@ucdenver.edu

stephen.russek@nist.gov

kathryn.keenan@nist.gov

Imaging phantoms are used to calibrate and validate the performance of magnetic resonance imaging (MRI) systems. Many new materials have been developed for additive manufacturing (three-dimensional [3D] printing) processes that may be useful in the direct printing or casting of dimensionally accurate, anatomically accurate, patient-specific, and/or biomimetic MRI phantoms. The $\mathrm{T}_{1}, \mathrm{~T}_{2}$, and $\mathrm{T}_{2}{ }^{*}$ spin relaxation times of polymer samples were tested to discover materials for use as tissue mimics and structures in MRI phantoms. This study included a cohort of polymer compounds that was tested in cured form. The cohort consisted of 101 standardized polymer samples fabricated from: two-part silicones and polyurethanes used in commercial casting processes; one-part optically cured polyurethanes used in 3D printing; and fused deposition thermoplastics used in 3D printing. The testing was performed at $3 \mathrm{~T}$ using inversion recovery, spin echo, and gradient echo sequences for $\mathrm{T}_{1}, \mathrm{~T}_{2}$, and $\mathrm{T}_{2}{ }^{*}$, respectively. $\mathrm{T}_{1}, \mathrm{~T}_{2}$, and $\mathrm{T}_{2}{ }^{*}$ values were plotted with error bars to allow the reader to assess how well a polymer matches a tissue for a specific application. A correlation was performed between $T_{1}, T_{2}, T_{2}$ * values and material density, elongation, tensile strength, and hardness. Two silicones, SI_XP-643 and SI_P-45, may be usable mimics for reported liver values; one silicone, SI_XP-643, may be a useful mimic for muscle; one silicone, SI_XP-738, may be a useful mimic for white matter; and four silicones, SI_P-15, SI_GI-1000, SI_GI-1040, and SI_GI-1110, may be usable mimics for spinal cord. Elongation correlated to $\mathrm{T}_{2}(p=0.0007)$, tensile strength correlated to $\mathrm{T}_{1}(p=0.002), \mathrm{T}_{2}(p=0.0003)$, and $\mathrm{T}_{2} *(p=0.003)$. The 80 samples not providing measurable signal with $\mathrm{T}_{1}, \mathrm{~T}_{2}, \mathrm{~T}_{2} *$ relaxation values too short to measure with the standard sequences, may be useful for MRI-invisible fixturing and medical devices at $3 \mathrm{~T}$.

Key words: 3D printing; medical imaging; MRI; phantom; polymer.

Accepted: June 16, 2020

Published: September 15, 2020

https://doi.org/10.6028/jres.125.028 


\section{Introduction}

Magnetic resonance imaging (MRI) has become an invaluable medical diagnostic tool in many applications [1-4]. MRI images are formed by placing a patient or material sample into a highly uniform magnetic field (B0) along the long $(z)$ axis of the scanner to align the proton spins of the tissue or material parallel with the field [5]. Typical clinical scanners, using superconducting magnets, operate at field values of $1.5 \mathrm{~T}$ and $3 \mathrm{~T}$, with $7 \mathrm{~T}$ clinical systems now becoming available. New low-field MRI scanners are also becoming available with fields below $100 \mathrm{mT}$. Additional magnetic field gradients $\left(G_{x}, G_{y}, G_{z}\right)$ are applied in the $x, y$, and $z$ directions for spatial encoding, along with transient radio-frequency (RF) magnetic field pulses, of amplitude B1, to excite the spins and tip them away from their equilibrium position. The B1 pulse, for which the frequency is at or near the precessional frequency of the nuclear spin being imaging, is generated from transverse-mounted RF coils. Most often, MRI detects the induced field produced by precessing proton spins on water and fat with a resonant frequency $\omega_{0}=\gamma_{p} B_{0}$, where $\gamma_{p}$ is the gyromagnetic ratio of the proton of interest, and resonant frequencies, $f_{0}=\omega_{0} / 2 \pi$, are approximately 63.9 $\mathrm{MHz}, 127.8 \mathrm{MHz}$, and $298 \mathrm{MHz}$ for $1.5 \mathrm{~T}, 3.0 \mathrm{~T}$, and $7 \mathrm{~T}$, respectively. The RF pulses, along with the gradient pulses, are choreographed into complex sequences to form the desired image. The RF pulses tip the proton spin moment by an angle $\alpha$, from parallel to the B0 field to typically $\alpha=90^{\circ}$ (perpendicular to the B0 field) or $\alpha=180^{\circ}$ (antiparallel to B0, $-z$ direction). The proton spin magnetization, $\boldsymbol{M}(t)$, will precess about $\mathrm{B} 0$ and relax back to its equilibrium value with different exponential decay rates, which are a function of material, molecular interactions, field strength, and temperature. The image contrast for many pulse sequences is set, to a large extent, by the relaxation times, denoted $\mathrm{T}_{1}, \mathrm{~T}_{2}$, and $\mathrm{T}_{2}{ }^{*}$, of different materials and tissues. ${ }^{1}$

$\mathrm{T}_{1}$ is the longitudinal relaxation time, which characterizes the time it takes to go from the initial excited $z$-axis magnetization, $M_{z i}$, to the equilibrium $z$-axis magnetization, $M_{0}$ :

$$
M_{z}(t)=M_{z i}+\left(M_{0}-M_{z i}\right)\left(1-e^{-\frac{t}{T_{1}}}\right)
$$

$\mathrm{T}_{2}$ is the transverse relaxation time and characterizes the decay of the transverse magnetization $\boldsymbol{M}_{x y}=$ $M_{x} \hat{x}+M_{y} \hat{y}$ to zero in the absence of any extrinsic dephasing effects:

$$
M_{x y}(t)=M_{t 0} e^{-i \omega_{0} t} e^{-\frac{t}{T_{2}}}
$$

where $M_{x y}=M_{x}+i M_{y}$ is the complex transverse magnetization, and $M_{t 0}$ is the initial magnetization just after the excitation pulse. $T_{2} *$ is the total dephasing time that includes effects due to intrinsic material properties ( $T_{2}$ relaxation) plus extrinsic field inhomogeneities due to sample or scanner created field inhomogeneities. From an operational perspective, $T_{2}$ describes the dephasing component that cannot be rephased by a spin echo sequence that incorporates rephasing pulses. $T_{2} *$ is always less than $T_{2}$ and is a function of the nonlocal environment. Since $T_{1}$ relaxation involves energy lost to adjacent macromolecules (spin-lattice), and $\mathrm{T}_{2}$ decay involves angular momentum transfer to adjacent spins (spin-spin), there may be material properties such as density, elongation, tensile strength, or hardness that correlate with $T_{1}, T_{2}$, and $\mathrm{T}_{2} *$ values, as they are sensitive to molecular structure and interactions [5].

\footnotetext{
${ }^{1}$ The MRI signal can be sensitive to several other material parameters, such as proton density, diffusion, electrical conductivity, and magnetic susceptibility, depending on the type of pulse sequence used. In this paper, we are only focusing on spin relaxation times.
} 
MRI calibration phantoms are used to assess stability in MRI scans over time, as well as establish consistency between manufacturers and models of scanners. These phantoms generally include accurately located vials of specific chemical solutions [6,7]. The fabrication of MRI phantoms historically involves machining and casting of large plastic components using manual and automated machining equipment. This approach involves considerable labor and machine time costs and feature detail that is limited to tool size and range of motion. The use of 3D printing for general medical applications is well documented, with multiple-material capability, improving accuracy, and decreasing costs of 3D printing technology rapidly developing [8-18]. These trends open opportunities to fabricate highly detailed calibration phantoms, as well as finely detailed patient-specific anatomical models for surgical planning and training. There are several studies describing the use of 3D printing materials and technology for MRI phantom applications [19-21].

In previous research, small numbers of two-part silicone and polyurethane polymers have been imaged with computed tomography (CT), MRI, and ultrasound [22, 23]. The results suggested that some of the materials might be suitable for use in $\mathrm{MRI} / \mathrm{CT} / \mathrm{ultrasound}$ imaging phantoms and mechanical test models. Additionally, the viscosities of the uncured polymer components appeared to be compatible with $3 \mathrm{D}$ printing through sub-millimeter-size nozzles.

This research was performed to discover or predict materials with $\mathrm{T}_{1}, \mathrm{~T}_{2}$, and $\mathrm{T}_{2} *$ relaxation values similar to human tissues for use as mimics, or, materials with no measurable relaxation values for use as MRI-compatible support structures. This study did not investigate the material's dielectric or magnetic susceptibility properties, which can also influence the MRI signal by distorting the RF and magnetic fields.

\section{Methods}

A list of the physical properties of candidate materials was compiled from manufacturer data sheets. The documented tissue values for $\mathrm{T}_{1}, \mathrm{~T}_{2}$, and $\mathrm{T}_{2}{ }^{*}$ at $3 \mathrm{~T}$ were obtained from peer-reviewed journal papers. The selection criteria for sample fabrication included availability within the project schedule, cost within available funding, ease and speed of fabrication, and toxicity that could be accommodated with standard protective gear and large room ventilation.

Samples of 3D printing materials were fabricated as $10 \mathrm{~mm} \times 15 \mathrm{~mm} \times 20 \mathrm{~mm}( \pm 0.01 \mathrm{~mm})$ cuboids. Standard samples of one-part ultraviolet-cured polyurethanes were printed with a FormLabs (Somerville, MA) (www.formlabs.com) Form 2 stereolithographic laser (SLA) printer. ${ }^{2}$ Standard samples of one-part polyurethanes and fused deposition modeling (FDM) materials were procured from third-party 3D printing fabricators Protocam (Allentown, PA) (www.protocam.com), Protogenic (Westminster, CO) (www.tenere.com), Protolabs (Maple Plain, MN) (www.protolabs.com), and Sculpteo (San Leandro, CA) (www.sculpteo.com). Since printer manufacturers offer materials optimized for each printer model and offer some compatibility with third-party materials, this sourcing strategy gave access to materials and chemistries from all major suppliers (3Dsystems, ALM, Carbon, Carbon Resin, DSM Somos, EOS, and Stratasys).

Samples of cured silicones were cut down to $20 \mathrm{~mm} \times 25 \mathrm{~mm} \times 5 \mathrm{~mm}( \pm 2 \mathrm{~mm})$ from precast material obtained from Silicones, Inc. (High Point, NC) (www.silicones-inc.com), and from Smooth-On, Inc. (Macungie, PA) (www.smooth-on.com). A sample of a two-part polyurethane from Huntsman (Woodlands, TX) (www.freeman.com) was also cut down. These sample sizes were chosen to ensure capture of at least one $4 \mathrm{~mm}$ coronal slice with enough protons for a detectable signal within a $6 \mathrm{~mm}$ diameter region of interest (ROI). Since $T_{1}$ and $T_{2}$ are intrinsic characteristics of materials and tissues, the exact dimensions of the samples were not relevant, provided enough protons were captured to emit a signal measurably above the scanner noise floor. $\mathrm{T}_{2} *$ measurements are affected by the sample geometry, since magnetic

${ }^{2}$ Certain commercial equipment, instruments, and/or materials are identified in this report in order to adequately specify the experimental procedure. Such identification does not imply recommendation or endorsement by the National Institute of Standards and Technology, nor does it imply that the equipment and/or materials used are necessarily the best available for the purpose. 
susceptibility variations can lead to additional field inhomogeneity. Care needs to be taken when associating $\mathrm{T}_{2} *$ values with material properties, particularly for materials with longer $\mathrm{T}_{2} *$ times, where the spin dephasing may be dominated by system and geometry inhomogeneities.

The test samples were placed in a 31 day commercial pill organizer (www.amazon.com), which exhibited no MRI signal at $3 \mathrm{~T}$ with the sequences used for testing. An Agilent 7T310 (Santa Clara, CA) (www.agilent.com) preclinical scanner operating at $3 \mathrm{~T}$ was used for the measurement of $\mathrm{T}_{1}, \mathrm{~T}_{2}$, and $\mathrm{T}_{2} *$ in this study. The scanner was equipped with a $140 \mathrm{~mm}$ quadrature birdcage RF coil from Doty Scientific (Columbia, SC) (www.dotynmr.com) with an isocenter accommodating 12 samples within the uniform field of view. To maintain coil loading between groups, one pill well in each group of 12 samples was filled with deionized (DI) water. The scanner used for this study was kept at a high level of calibration for quantitative imaging phantom development at the National Institute of Standards and Technology (NIST).

The MRI sequences listed in Table A1 were used to obtain $T_{1}, T_{2}$, and $T_{2}{ }^{*}$ values using a single $4 \mathrm{~mm}$ coronal ( $x-z$ plane) slice. The RF coil was retuned and matched at $50 \mathrm{ohms}$ for the imaging of each section to accommodate the variable loading of samples.

The $T_{1}, T_{2}$, and $T_{2} *$ relaxation times of the samples were obtained from series of magnitude images obtained from conventional inversion recovery, spin echo, and gradient echo sequences, respectively [24]. The inversion recovery sequence tips the spins by $\alpha=180^{\circ}$ and then waits an inversion time (TI) before tipping the spins into the transverse plane and detecting the induced signal. The spin echo sequence tips the spins by $\alpha=90^{\circ}$ and then, after a time TE/2, applies a refocusing pulse and records the signal at echo time TE. For the gradient echo sequence, the spins are tipped $\alpha=90^{\circ}$, and then the signal is read at a time TE without any refocusing. For $\mathrm{T}_{1}$, the inversion time, TI, was varied, and for $\mathrm{T}_{2}$ and $\mathrm{T}_{2}{ }^{*}$, the echo time, TE, was varied. The relaxation times were computed using the Python-based NIST PhantomViewer software application (www.github.com/NIST/PhantomViewer) by fitting the observed signal, $S$, to the models described in Eq. (3) for $T_{1}$ and Eq. (4) for $T_{2}$ and $T_{2} *$. Standard nonlinear least squares fit routines (Levenberg Marquardt) from the Scipy library (www.scipy.org/scipylib) were used.

$$
\begin{gathered}
S(T I)=\mathrm{A} \mid 1-\mathrm{B} e^{-\frac{T I}{T_{1}} \mid} . \\
S(T E)=S_{0} e^{-\frac{T E}{T_{2}}} .
\end{gathered}
$$

The initial parameter guesses for the nonlinear least squares fitting were $\mathrm{T}_{1 \text { guess }}=\mathrm{TI}_{\mathrm{amin}} / \ln 2$ for $\mathrm{T}_{1}$ and $\mathrm{T}_{2 \text { guess }}=200 \mathrm{~ms}$ for $\mathrm{T}_{2}$ fitting, where $\mathrm{TI}_{\mathrm{amin}}$ is the value of $\mathrm{TI}$ that gives a minimum signal. The computed relaxation values and error bars were plotted alongside tissue relaxation values and error bars taken from literature.

To uncover predictive relationships, the measured $\mathrm{T}_{1}, \mathrm{~T}_{2}$, and $\mathrm{T}_{2}{ }^{*}$ values were plotted against the physical properties listed by the manufacturers, in addition to a least squares statistical analysis performed using the JMP (Cary, NC) (www.jmp.com) software application. Materials with $R^{2}>0.5$ and $p<0.05$ were considered statistically significant for the purposes of this exploratory study.

\section{Results}

The properties of over 1200 castable and printable materials were reviewed for use as mimics for human tissues. Many of the human tissue values are cited by the original sources in this study [25-43] and are summarized by Bojorquez et al. [33]. The $\mathrm{T}_{1}$ and, $\mathrm{T}_{2}$ values for tissues found in literature are provided in Table A2 sorted alphabetically. 


\section{Journal of Research of the National Institute of Standards and Technology}

Materials with signals below the noise level and $\mathrm{T}_{1}, \mathrm{~T}_{2}, \mathrm{~T}_{2} *$ values too short to measure using standard pulse sequences, are provided in Table S1 along with their physical characteristics.

The $T_{1}, T_{2}$, and $T_{2}{ }^{*}$ values of the samples that had measurable values are listed in Table A3 for materials, sorted by increasing $T_{1}$ value, along with their respective physical properties. The samples exhibiting measurable signal are shown in a photo of the tray in Fig. 1.

(A)
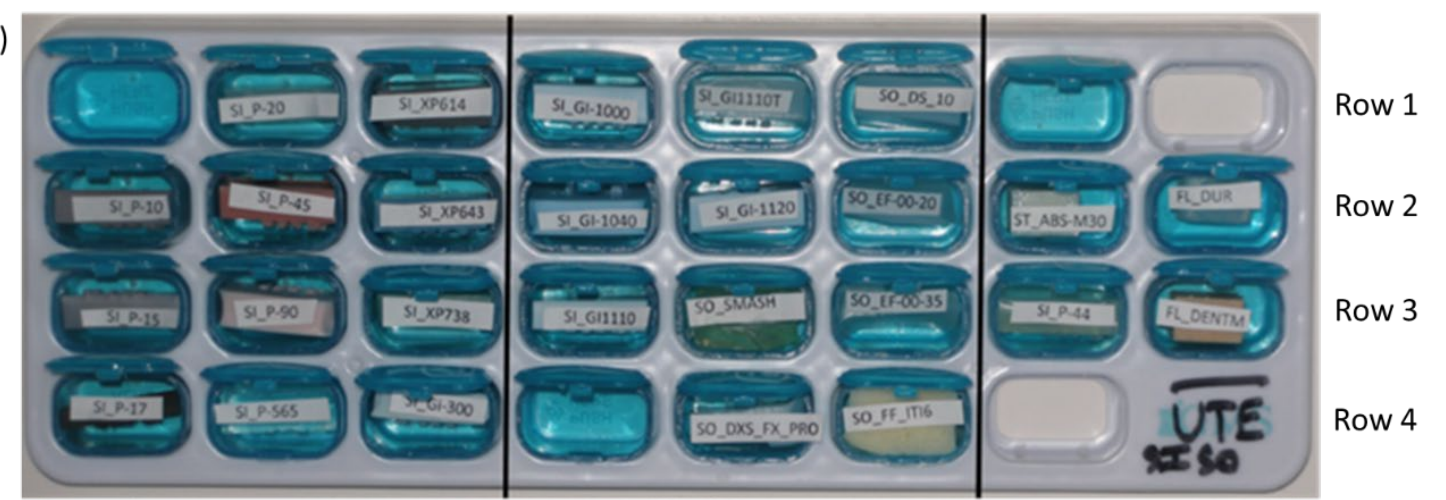

(B)
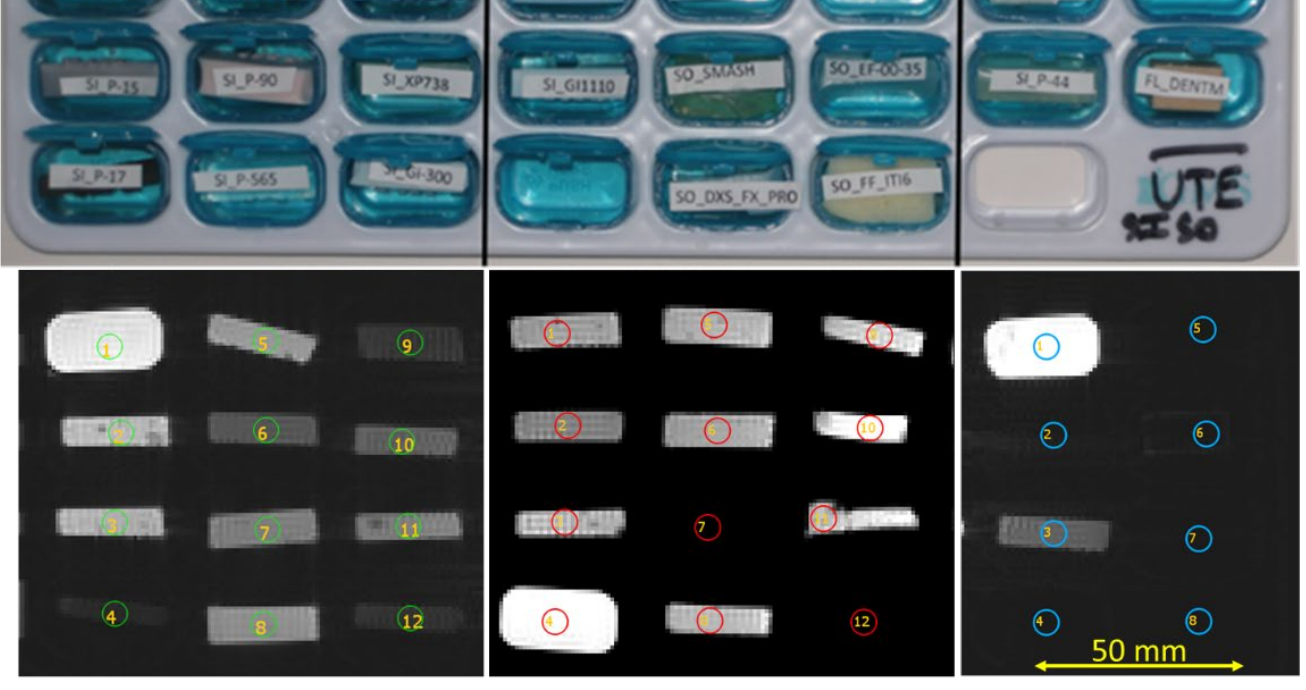

Fig. 1. (A) Pill organizer loaded with labeled material samples in pill wells and (B) corresponding coronal gradient echo $\left(\mathrm{T}_{2}{ }^{*}\right)$ images at TE 2.9 ms (sections 1-3). Sample list:

Row 1 - water, SI P-20, SI XP614, SI GI1000, SI GI1110T, SO DS 10, water, empty;

Row 2 - SI_P-10, SI_P-45, SI_643, SI_GI-1040, SI_GI-1120, SO_EF-00-20, ST_ABS-M30, FL_Dur; Row 3 - SI P-15, SI P-90, SI XP738, SI GI1110, SO SMASH, SOEF-00-35, SI P-44, FL DENTM; Row 4 - SI_P-17, SI_P-565, SI_GI-300, water, SO_DXS_FX_PRO, SO_FF_ITI6, empty.

The $\mathrm{T}_{1}, \mathrm{~T}_{2}$, and $\mathrm{T}_{2}{ }^{*}$ values of the materials and values of human tissue are plotted in Fig. 2 (a)-(c), with error bars where error data were available. Error bars were truncated on the top chart margin in favor of reducing plot detail. Since all error bars are symmetric, the truncated upper values can be deduced from the lower error bar. 


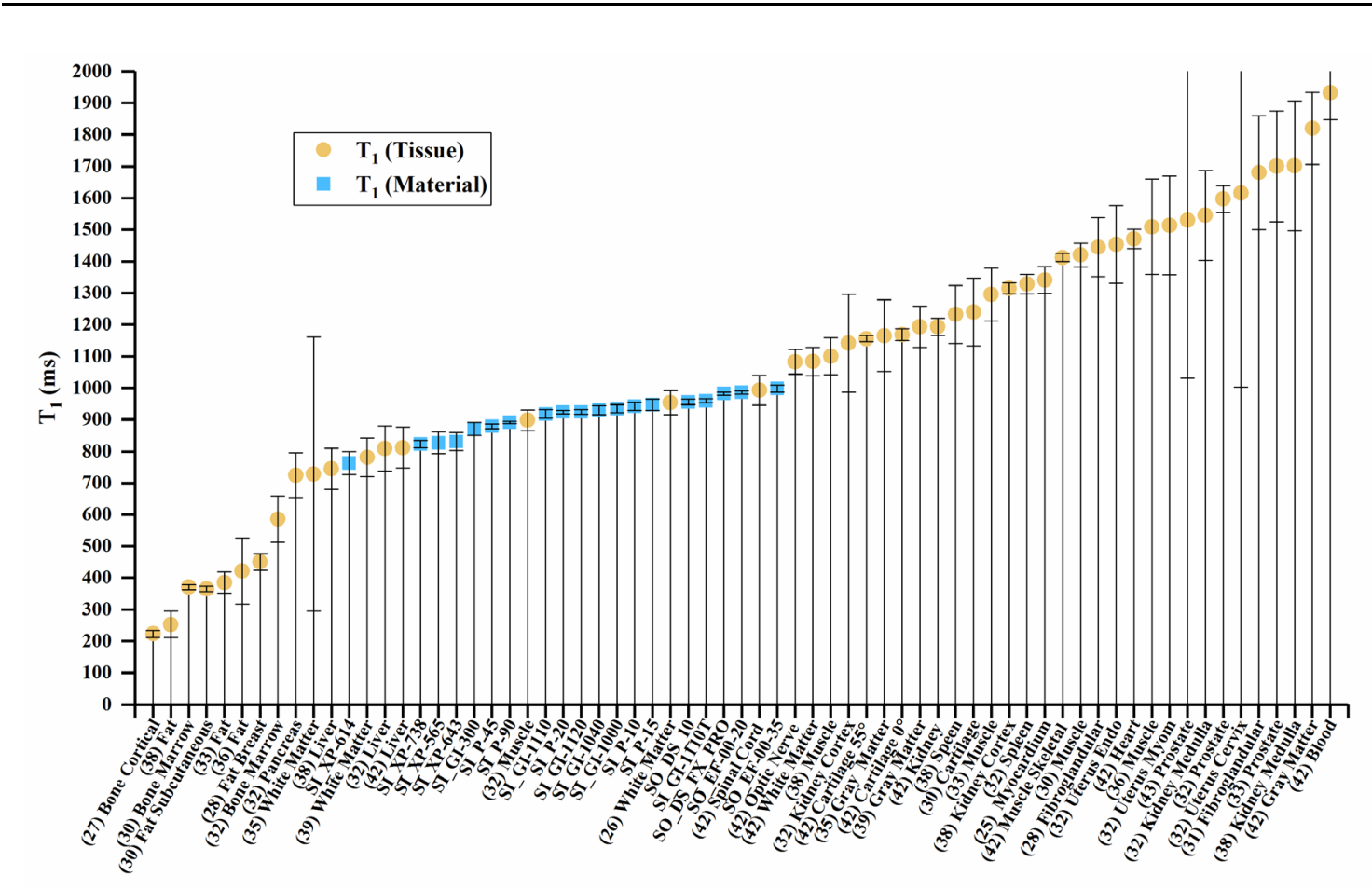

(a)

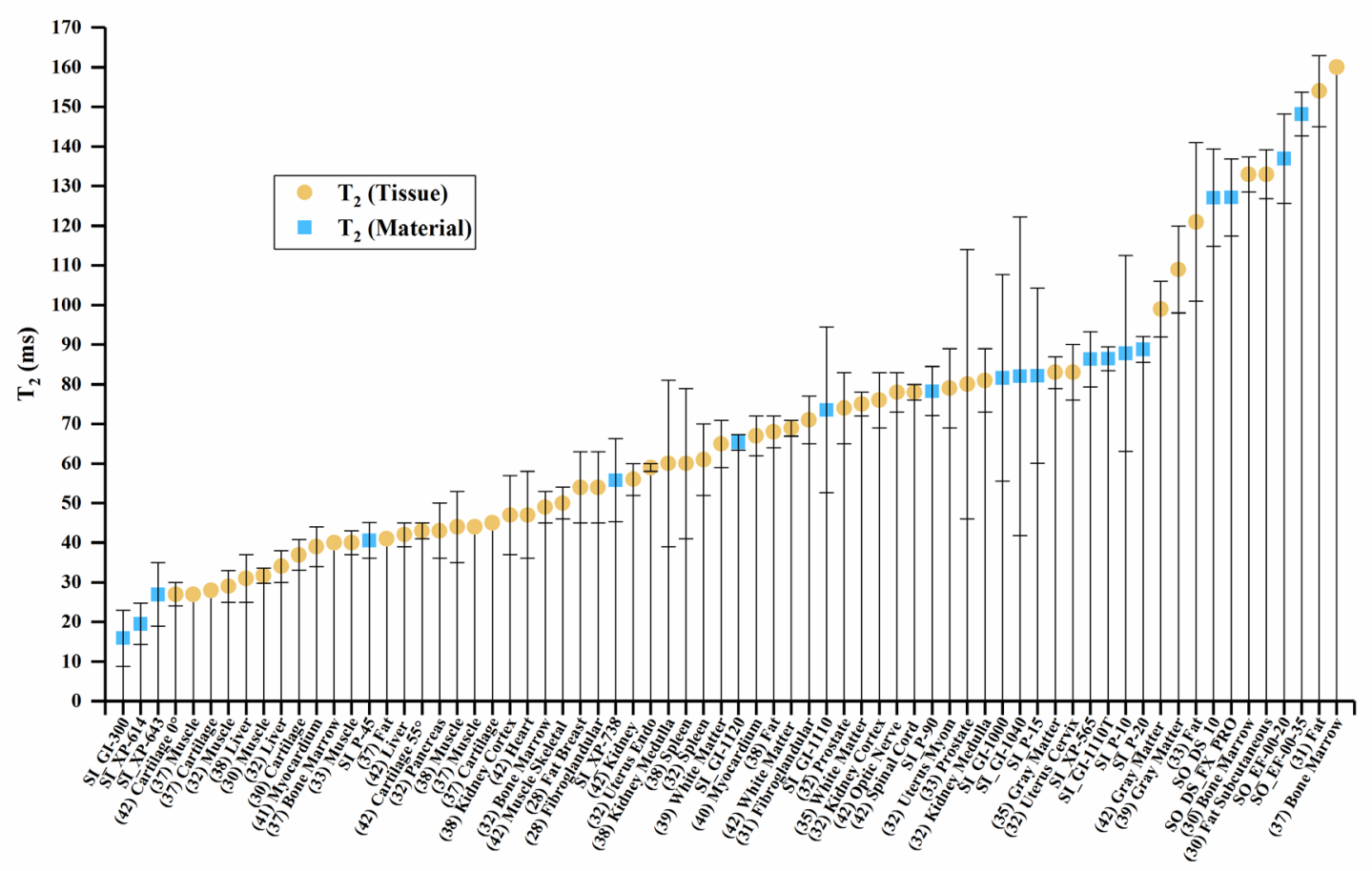

(b) 


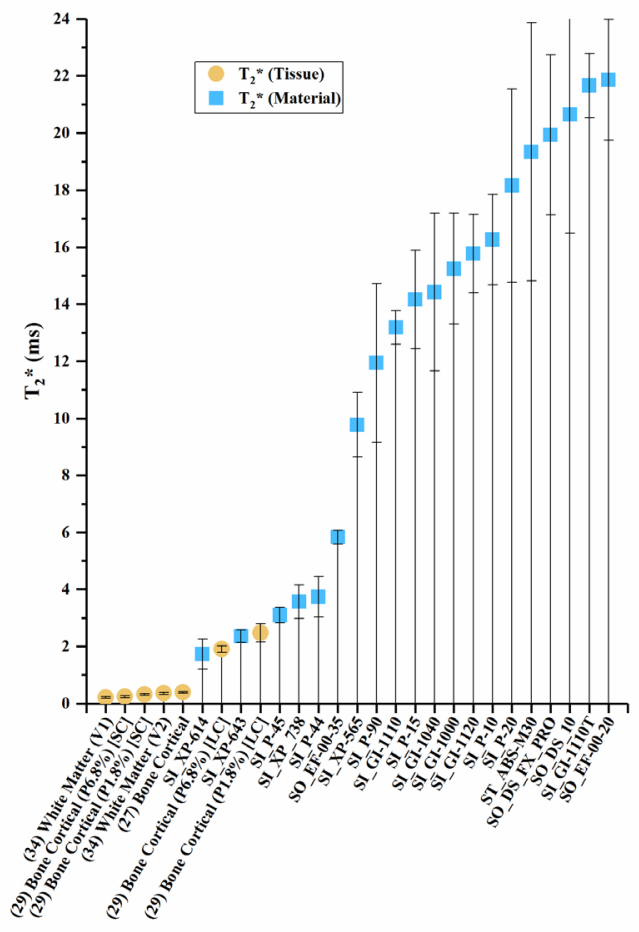

(c)

Fig. 2. (a) Sample material $T_{1}$ values compared to human tissues. (b) Sample material $T_{2}$ values compared to human tissues. (c) Sample material $\mathrm{T}_{2}{ }^{*}$ values compared to human tissues, where $\mathrm{SC}$ indicates the short compartment of $\mathrm{T}_{2}{ }^{*}$, and LC indicates the long compartment $\mathrm{T}_{2}^{*}, \mathrm{Px} . \mathrm{x} \%$ is porosity percent, and $(\mathrm{Vx})$ is Volunteer \#.

The $T_{1}$ vs. $T_{2}, T_{1}$ vs. $T_{2}{ }^{*}$, and $T_{2}$ vs. $T_{2} *$ values are plotted in Fig. 3 (a)-(d) overlaid with values of human tissues, with error bars where error data were available. Error bars were truncated on the top chart margin in favor of reducing plot detail. Since all error bars are symmetric, the truncated upper values can be deduced from the lower error bar. 
Journal of Research of the National Institute of Standards and Technology

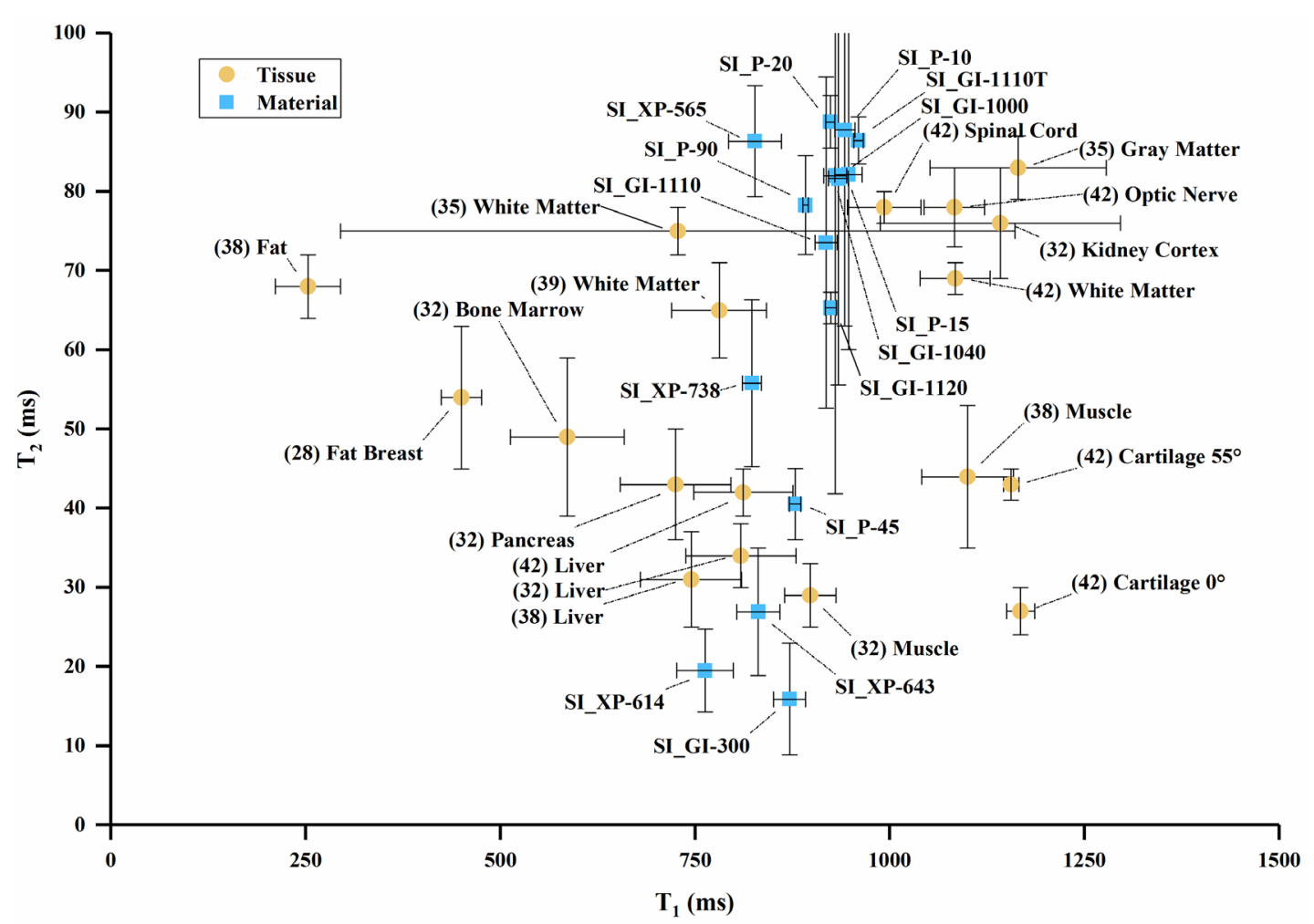

(a)

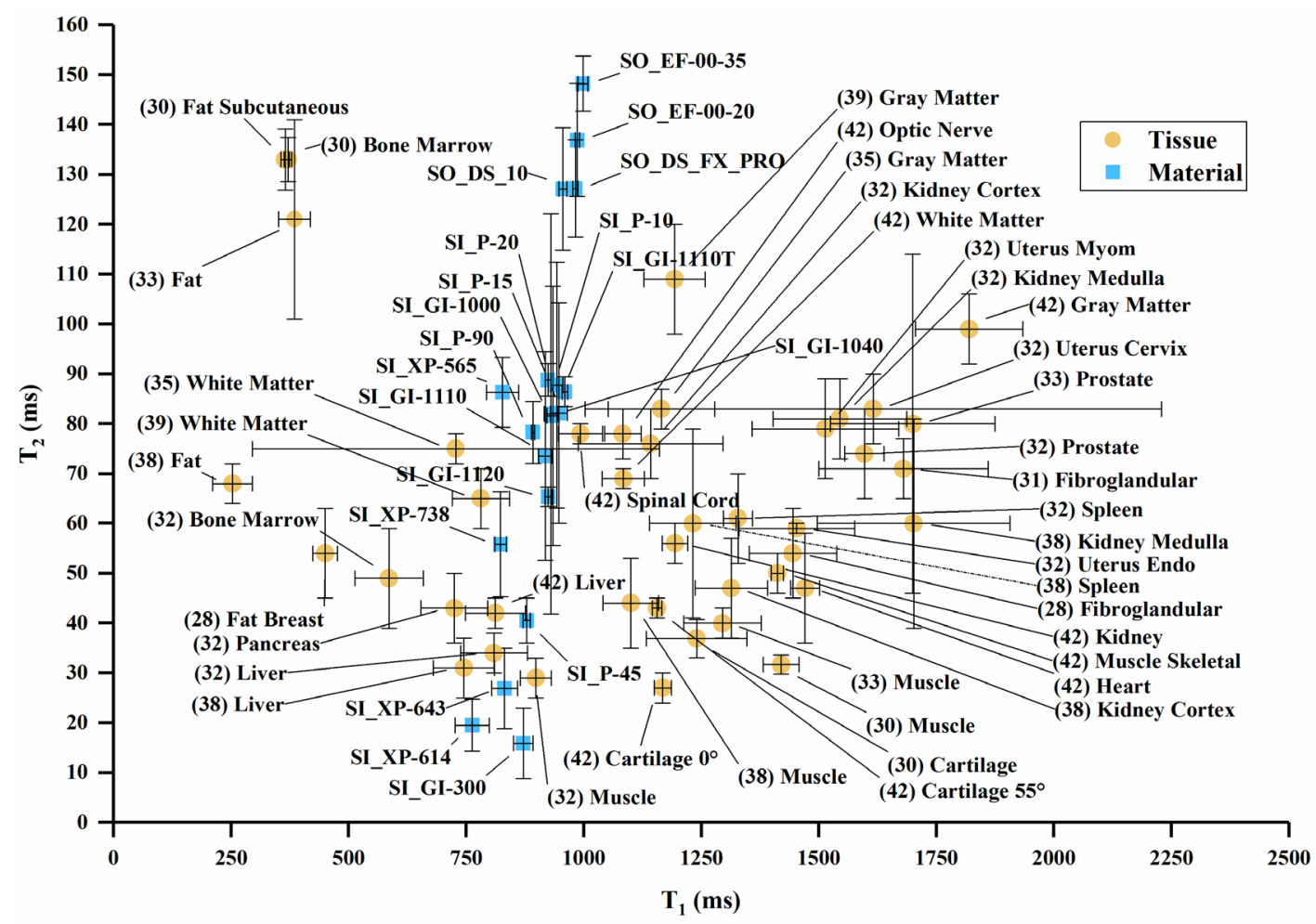

(b) 


\section{Journal of Research of the National Institute of Standards and Technology}

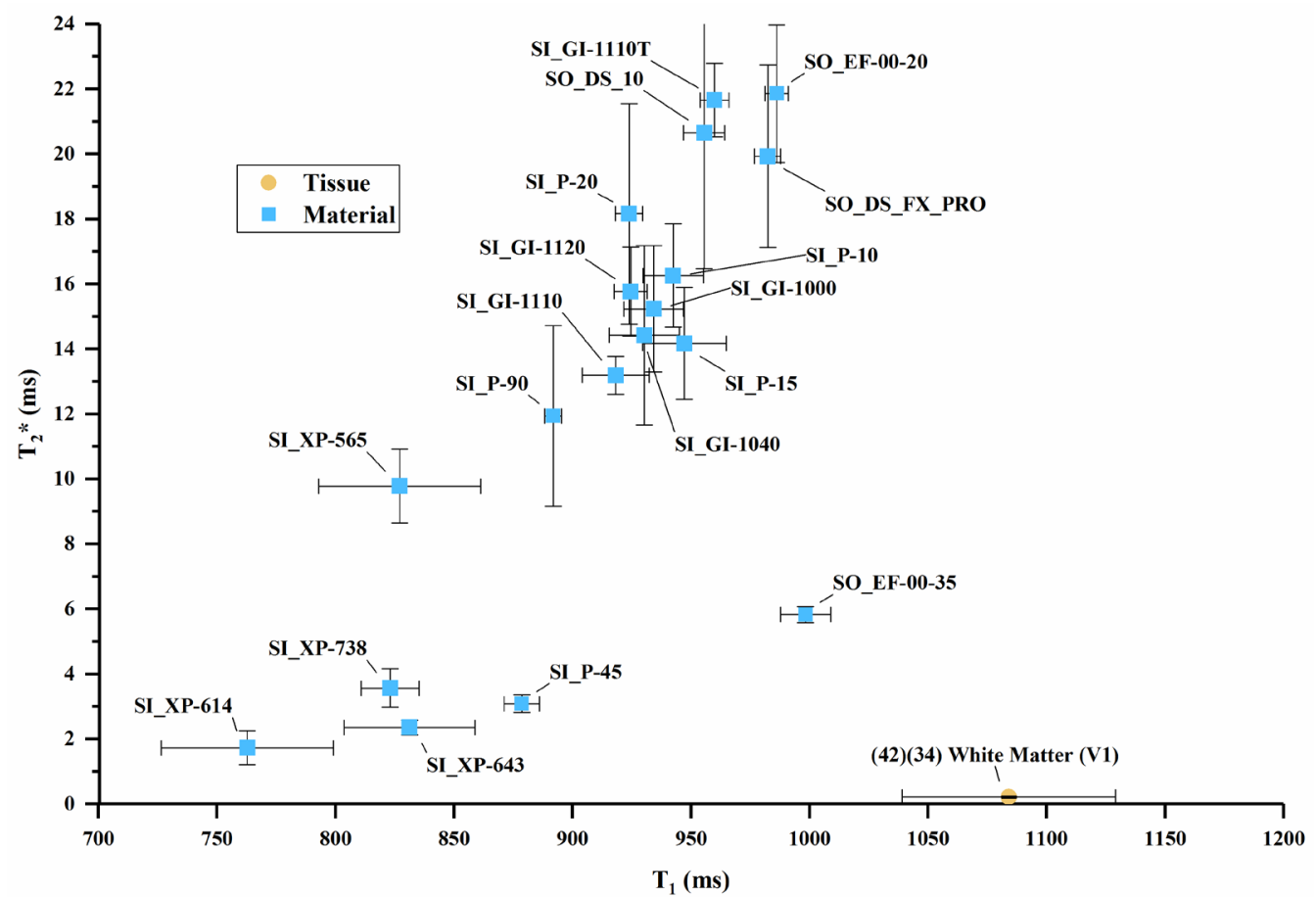

(c)

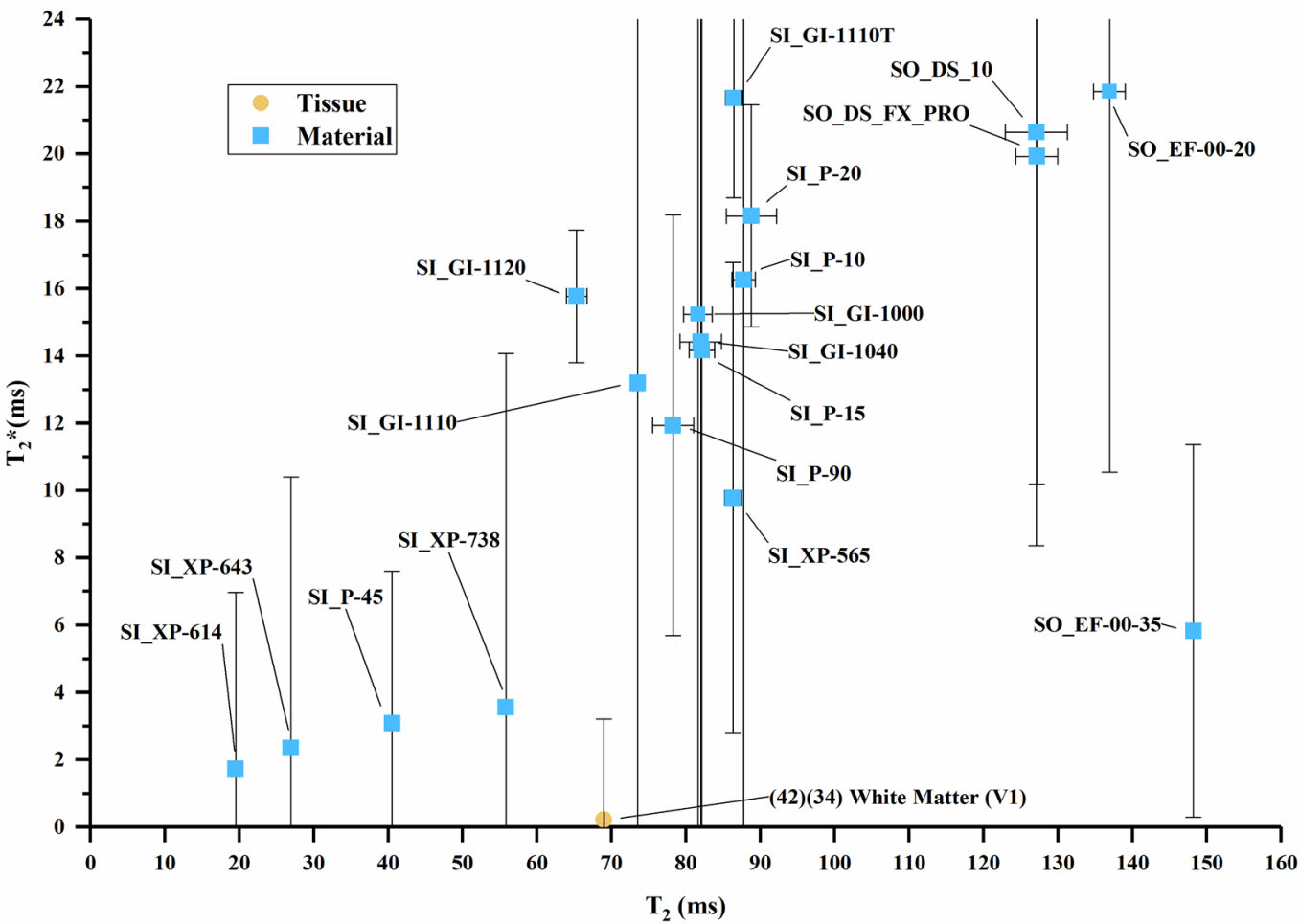

(d)

Fig. 3. (a) $T_{1}$ vs. $T_{2}$ values for sample materials near human tissue values. (b) $T_{1}$ vs. $T_{2}$ values for sample materials compared to many human tissues. (c) $T_{1}$ vs. $T_{2}{ }^{*}$ values for sample materials. (d) $T_{2}$ vs. $T_{2}{ }^{*}$ values for sample materials. Note: (1) The white matter data point combines $T_{2} *$ and $T_{1}$ data from two authors in Table A3 [34, 42]. (2) Cortical bone values plot below the axis scale $\left[T_{1}=223\right.$ $\left.\mathrm{ms}, \mathrm{T}_{2}=11 \mathrm{~ms}, \mathrm{~T}_{2} *=0.39 \mathrm{~ms}\right][27]$. 
A summary of the statistical analysis is provided in Table A4 and in Figs. S1-12, including $R^{2}, p$ values, and fit model. Elongation correlated to $\mathrm{T}_{2}(p=0.0007)$, and tensile strength correlated to $\mathrm{T}_{1}(p=$ $0.002), \mathrm{T}_{2}(p=0.0003)$, and $\mathrm{T}_{2} *(p=0.003)$. Density and hardness did not correlate to relaxation values.

\section{Discussion}

There were several materials for which the measured $T_{1}$ and $T_{2}$ values were near tissue values. The materials with measurable $T_{1}, T_{2}$, and $T_{2} *$ values using the available MRI sequences were cast silicones, although $\mathrm{T}_{1}, \mathrm{~T}_{2}$, and $\mathrm{T}_{2} *$ were not predicted by silicone condensation or addition cure chemistry. The statistical analysis showed that $\mathrm{T}_{2}$ increased with increasing material elongation, suggesting that increased molecular distance reduced the opportunity for spin-spin energy transfer. The other significant correlation was that $\mathrm{T}_{1}, \mathrm{~T}_{2}$, and $\mathrm{T}_{2} *$ decreased with increasing tensile strength, suggesting that increasing molecular rigidity increased spin-lattice and spin-spin coupling. $T_{1}, T_{2}$, and $T_{2} *$ were not predicted by density or hardness.

The relaxation values for the $3 \mathrm{D}$ printed thermoplastics and polyurethanes were not measurable with the scanner and sequences used in the study due to short decay times. Future research will be conducted on a scanner capable of running ultrashort (UTE) sequences to determine if the "no signal" and "no fit" samples from this research have use as mimics for short $\mathrm{T}_{2} *$ tissues. These low-signal materials might be used in the fabrication of very precise MRI-compatible fixtures and accessories such as RF and gradient coil housings, magnetic probe holders, patient head and body alignment fixtures, or functional MRI actuators to name a few examples.

The study was limited by several factors. Only the four material characteristics evaluated in this study were consistently reported by all manufacturers. Few peer-reviewed papers reported $\mathrm{T}_{1}, \mathrm{~T}_{2}$, and $\mathrm{T}_{2}$ * for the same tissue because most papers focused on one or two of the three relaxation times due to lack of instrumentation. The intimate details of each material's chemistry and processing were not known, so the size and mobility of the molecules were not known. Future chemistry knowledge might explain some apparent groupings in the density plots and justify separate fits in future analyses.

Given this study was performed at $3 \mathrm{~T}$ and that tissue and material $\mathrm{T}_{1}, \mathrm{~T}_{2}$, and $\mathrm{T}_{2}$ * relaxation times change with field strength, it is expected that the relative material/tissue values would be different at $1.5 \mathrm{~T}$ and $7 \mathrm{~T}$.

\section{Conclusion}

Two silicones, SI_XP-643 $\left(\mathrm{T}_{1}=831.3 \mathrm{~ms}, \mathrm{~T}_{2}=26.9 \mathrm{~ms}\right)$ and SI_P-45 $\left(\mathrm{T}_{1}=878.6 \mathrm{~ms}, \mathrm{~T}_{2}=40.5 \mathrm{~ms}\right)$, may be usable mimics for reported liver values; one silicone, SI_XP-643 $\left(\mathrm{T}_{1}=831.3 \mathrm{~ms}, \mathrm{~T}_{2}=26.9 \mathrm{~ms}\right)$, may be a useful mimic for muscle; one silicone, SI_XP-738 $\left(\mathrm{T}_{1}=823.0 \mathrm{~ms}, \mathrm{~T}_{2}=55.8 \mathrm{~ms}\right)$, may be a useful mimic for white matter; and four silicones, SI_P-15 $\left(\mathrm{T}_{1}=947.2 \mathrm{~ms}, \mathrm{~T}_{2}=82.1 \mathrm{~ms}\right)$, SI_GI-1000 $\left(\mathrm{T}_{1}=934.2\right.$ $\left.\mathrm{ms}, \mathrm{T}_{2}=81.2 \mathrm{~ms}\right)$, SI_GI-1040 $\left(\mathrm{T}_{1}=930.26 \mathrm{~ms}, \mathrm{~T}_{2}=81.99 \mathrm{~ms}\right)$, and SI_GI-1110 $\left(\mathrm{T}_{1}=918.2 \mathrm{~ms}\right.$, $\left.\mathrm{T}_{2}=73.5 \mathrm{~ms}\right)$, may be usable mimics for spinal cord [32, 38, 39, 42]. Elongation correlated to $\mathrm{T}_{2}(p=$ $0.0007)$, and tensile strength correlated to $\mathrm{T}_{1}(p=0.002), \mathrm{T}_{2}(p=0.0003)$, and $\mathrm{T}_{2} *(p=0.003)$. The 80 samples not providing measurable $\mathrm{T}_{1}, \mathrm{~T}_{2}$, and $\mathrm{T}_{2} *$ relaxation times with the standard sequences used in this study should be good candidates for MRI-compatible fixtures and medical devices at $3 \mathrm{~T}$. 


\section{Journal of Research of the National Institute of Standards and Technology}

\section{Appendix A}

Table A1. MRI sequences.

\begin{tabular}{|c|c|c|c|c|c|c|c|}
\hline $\mathrm{T}$ & Sequence & $\begin{array}{l}\text { Feld of } \\
\text { View } \\
(\mathrm{mm})\end{array}$ & $\begin{array}{l}\text { Resolution } \\
x \times z \\
(\mathrm{~mm})\end{array}$ & $\begin{array}{l}\mathrm{TR}^{\mathrm{a}} \\
(\mathrm{ms})\end{array}$ & TE, TI (ms) & $\begin{array}{c}\text { Flip } \\
\text { Angle } \\
\text { (degree) }\end{array}$ & Average \\
\hline$\overline{T_{1}}$ & $\begin{array}{l}\text { Spin echo } \\
\text { inversion } \\
\text { recovery }\end{array}$ & 120 & $\begin{array}{l}128 \times 128 \\
0.93\end{array}$ & 10,000 & $\begin{array}{l}\text { TE } 10.86 \\
\text { TI } 10,18,32.5,58.5,105 \text {, } \\
190,342,616,1110,2000\end{array}$ & $\begin{array}{c}180 \\
90\end{array}$ & 1 \\
\hline $\mathrm{T}_{2}$ & Spin echo & 120 & $\begin{array}{l}256 \times 256 \\
0.47\end{array}$ & 10,000 & $\begin{array}{l}\text { TE } 15,30,60,120,240, \\
480,960\end{array}$ & 90 & 1 \\
\hline $\mathrm{T}_{2}{ }^{*}$ & Gradient echo & 120 & $\begin{array}{l}128 \times 128 \\
0.93\end{array}$ & 1000 & $\begin{array}{l}\text { TE } 2.9,5.8,11.6, \\
23.2,46.4,92.8,185.6\end{array}$ & 90 & 8 \\
\hline
\end{tabular}

${ }^{\mathrm{a}}(\mathrm{TR})$ repetition time, $(\mathrm{TE})$ echo time, $(\mathrm{TI})$ inversion time.

Table A2. Tissue values reported in literature.

\begin{tabular}{|c|c|c|c|c|c|c|c|}
\hline Material $^{\mathrm{a}}$ & $\begin{array}{r}\mathrm{T}_{1} \\
(\mathrm{~ms}) \\
\end{array}$ & $\begin{array}{r}T_{1} \text { Error } \\
(\mathrm{ms}) \\
\end{array}$ & $\begin{array}{r}\mathrm{T}_{2} \\
(\mathrm{~ms}) \\
\end{array}$ & $\begin{array}{r}\mathrm{T}_{2} \text { Error } \\
(\mathrm{ms}) \\
\end{array}$ & $\begin{array}{r}\mathrm{T}_{2}{ }^{*} \\
(\mathrm{~ms}) \\
\end{array}$ & $\begin{array}{r}\mathrm{T}_{2}{ }^{*} \text { Error } \\
(\mathrm{ms}) \\
\end{array}$ & Ref. \\
\hline Blood & 1932 & 85 & 275 & 50 & & & 42 \\
\hline Bone cortical & 223 & 11 & & & & & 27 \\
\hline Bone cortical & & & & & 0.39 & 0.019 & 27 \\
\hline Bone cortical (P1.8\%) [LC] & & & & & 2.47 & 0.323 & 29 \\
\hline Bone cortical (P1.8\%) $[\mathrm{SC}]$ & & & & & 0.318 & 0.024 & 29 \\
\hline Bone cortical (P6.8\%) [LC] & & & & & 1.904 & 0.112 & 29 \\
\hline Bone cortical (P6.8\%) [SC] & & & & & 0.237 & 0.037 & 29 \\
\hline Bone marrow & & & 160 & & & & 37 \\
\hline Bone marrow & 586 & 73 & 49 & 10 & & & 32 \\
\hline Bone marrow & 371 & 7.9 & 133 & 4.43 & & & 30 \\
\hline Bone marrow & & & 40 & & & & 37 \\
\hline Cartilage & 1240 & 107 & 36.9 & 3.81 & & & 30 \\
\hline Cartilage & & & 28 & & & & 37 \\
\hline Cartilage & & & 45 & & & & 37 \\
\hline Cartilage $0^{\circ}$ & 1168 & 18 & 27 & 3 & & & 42 \\
\hline Cartilage $55^{\circ}$ & 1156 & 10 & 43 & 2 & & & 42 \\
\hline Fat & 421 & 104 & & & & & 36 \\
\hline Fat & 385 & 34 & 121 & 20 & & & 33 \\
\hline Fat & 253 & 42 & 68 & 4 & & & 38 \\
\hline Fat & & & 154 & 9 & & & 31 \\
\hline Fat & & & 41 & & & & 37 \\
\hline Fat breast & 450 & 26 & 54 & 9 & & & 28 \\
\hline Fat subcutaneous & 365 & 9 & 133 & 6.14 & & & 30 \\
\hline Fibroglandular & 1680 & 180 & 71 & 6 & & & 31 \\
\hline Fibroglandular & 1445 & 93 & 54 & 9 & & & 28 \\
\hline Gray matter & 1193 & 65 & 109 & 11 & & & 39 \\
\hline Gray matter & 1165 & 113 & 83 & 4 & & & 35 \\
\hline Gray matter & 1820 & 114 & 99 & 7 & & & 42 \\
\hline Heart & 1471 & 31 & 47 & 11 & & & 42 \\
\hline Kidney & 1194 & 27 & 56 & 4 & & & 42 \\
\hline Kidney cortex & 1314 & 77 & 47 & 10 & & & 38 \\
\hline Kidney cortex & 1142 & 154 & 76 & 7 & & & 32 \\
\hline Kidney medulla & 1702 & 205 & 60 & 21 & & & 38 \\
\hline Kidney medulla & 1545 & 142 & 81 & 8 & & & 32 \\
\hline
\end{tabular}


Volume 125, Article No. 125028 (2020) https://doi.org/10.6028/jres.125.028

Journal of Research of the National Institute of Standards and Technology

\begin{tabular}{|c|c|c|c|c|c|c|c|}
\hline Material $^{\mathrm{a}}$ & $\begin{array}{r}\mathrm{T}_{1} \\
(\mathrm{~ms}) \\
\end{array}$ & $\begin{array}{r}\mathrm{T}_{1} \text { Error } \\
(\mathrm{ms}) \\
\end{array}$ & $\begin{array}{r}\mathrm{T}_{2} \\
(\mathrm{~ms}) \\
\end{array}$ & $\begin{array}{r}\mathrm{T}_{2} \text { Error } \\
(\mathrm{ms}) \\
\end{array}$ & $\begin{array}{r}\mathrm{T}_{2} * \\
(\mathrm{~ms}) \\
\end{array}$ & $\begin{array}{r}\mathrm{T}_{2}{ }^{*} \text { Error } \\
(\mathrm{ms})\end{array}$ & Ref. \\
\hline Liver & 745 & 65 & 31 & 6 & & & 38 \\
\hline Liver & 809 & 71 & 34 & 4 & & & 32 \\
\hline Liver & 812 & 64 & 42 & 3 & & & 42 \\
\hline Muscle & 1509 & 150 & & & & & 36 \\
\hline Muscle & 1295 & 83 & 40 & 3 & & & 33 \\
\hline Muscle & 1100 & 59 & 44 & 9 & & & 38 \\
\hline Muscle & 898 & 33 & 29 & 4 & & & 32 \\
\hline Muscle & 1420 & 38 & 31.7 & 1.9 & & & 30 \\
\hline Muscle & & & 27 & & & & 37 \\
\hline Muscle & & & 44 & & & & 37 \\
\hline Muscle skeletal & 1412 & 13 & 50 & 4 & & & 42 \\
\hline Myocardium & 1341 & 42 & & & & & 25 \\
\hline Myocardium & & & 67 & 5 & & & 40 \\
\hline Myocardium [L] & & & 39 & 5 & & & 41 \\
\hline Optic nerve & 1083 & 39 & 78 & 5 & & & 42 \\
\hline Pancreas & 725 & 71 & 43 & 7 & & & 32 \\
\hline Prostate & 1700 & 175 & 80 & 34 & & & 33 \\
\hline Prostate & 1597 & 42 & 74 & 9 & & & 32 \\
\hline Prostate & 1530 & 498 & & & & & 43 \\
\hline Spinal cord & 993 & 47 & 78 & 2 & & & 42 \\
\hline Spleen & 1232 & 92 & 60 & 19 & & & 38 \\
\hline Spleen & 1328 & 31 & 61 & 9 & & & 32 \\
\hline Uterus cervix & 1616 & 613 & 83 & 7 & & & 32 \\
\hline Uterus endo & 1453 & 123 & 59 & 1 & & & 32 \\
\hline Uterus myom & 1514 & 156 & 79 & 10 & & & 32 \\
\hline White matter & 781 & 61 & 65 & 6 & & & 39 \\
\hline White matter & 728 & 433 & 75 & 3 & & & 35 \\
\hline White matter & 954 & 39 & & & & & 26 \\
\hline White matter & 1084 & 45 & 69 & 2 & & & 42 \\
\hline White matter (V1) & & & & & 0.216 & 0.03 & 34 \\
\hline White matter (V2) & & & & & 0.358 & 0.036 & 34 \\
\hline
\end{tabular}

${ }^{\mathrm{a}} \mathrm{SC} / \mathrm{LC}=$ short/long compartment of $\mathrm{T}_{2} * ; \mathrm{Px} . \mathrm{x} \%=$ porosity, $\mathrm{V} x=$ volunteer $x$. 


\section{Journal of Research of the National Institute of Standards and Technology}

Table A3. Sample properties and measured $\mathrm{T}_{1}, \mathrm{~T}_{2}$, and $\mathrm{T}_{2} *$ values.

\begin{tabular}{|c|c|c|c|c|c|c|c|c|c|c|c|c|}
\hline $\begin{array}{l}\text { Print/ } \\
\text { Cast }^{\text {a }} \\
\end{array}$ & Fabrication $^{\mathrm{b}}$ & Sample Name ${ }^{\mathrm{c}}$ & $\begin{array}{l}\text { Density } \\
\left(\mathrm{kg} / \mathrm{m}^{3}\right) \\
\end{array}$ & $\begin{array}{c}\text { Elong }^{\mathrm{d}} \\
(\%) \\
\end{array}$ & $\begin{array}{c}\mathrm{TS}^{\mathrm{d}} \\
(\mathrm{MPa}) \\
\end{array}$ & $\begin{array}{c}\operatorname{Hard}^{\mathrm{d}} \\
(\mathrm{SA}) \\
\end{array}$ & $\begin{array}{c}\mathrm{T}_{1} \\
(\mathrm{~ms}) \\
\end{array}$ & $\begin{array}{c}\mathrm{T}_{1} \\
\text { Error } \\
\text { (ms) } \\
\end{array}$ & $\begin{array}{r}\mathrm{T}_{2} \\
(\mathrm{~ms}) \\
\end{array}$ & $\begin{array}{c}\mathrm{T}_{2} \\
\text { Error } \\
(\mathrm{ms}) \\
\end{array}$ & $\begin{array}{l}\mathrm{T}_{2}{ }^{*} \\
(\mathrm{~ms}) \\
\end{array}$ & $\begin{array}{c}\mathrm{T}_{2}{ }^{*} \\
\text { Error } \\
(\mathrm{ms}) \\
\end{array}$ \\
\hline Cast & Silicone (add) & SI_XP-614 & 1240 & 175.0 & 4.1 & 23.0 & 762.8 & 36.2 & 19.5 & 5.2 & 1.7 & 0.5 \\
\hline Cast & Silicone (add) & SI_XP-738 & 1990 & 600.0 & 4.8 & 45.0 & 823.0 & 12.2 & 55.8 & 10.5 & 3.6 & 0.6 \\
\hline Cast & Silicone (add) & SI_XP-565 & 1020 & ND & ND & 27.0 & 827.1 & 34.2 & 86.3 & 7.0 & 9.8 & 1.1 \\
\hline Cast & Silicone (add) & SI_XP-643 & 1130 & 700.0 & 5.0 & 40.0 & 831.3 & 27.6 & 26.9 & 8.0 & 2.4 & 0.2 \\
\hline Cast & Silicone (cond) & SI_GI-300 & 1350 & 160.0 & 4.1 & 47.5 & 871.6 & 20.6 & 15.9 & 7.1 & NF & NF \\
\hline Cast & Silicone (add) & SI_P-45 & 1120 & 275.0 & 5.5 & 42.0 & 878.6 & 7.5 & 40.5 & 4.5 & 3.1 & 0.3 \\
\hline Cast & Silicone (add) & SI_P-90 & 1130 & 415.0 & 4.1 & 59.0 & 891.9 & 3.5 & 78.3 & 6.2 & 11.9 & 2.8 \\
\hline Cast & Silicone (cond) & SI_GI-1110 & 1080 & 450.0 & 1.9 & 6.0 & 918.2 & 14.2 & 73.5 & 20.9 & 13.2 & 0.6 \\
\hline Cast & Silicone (add) & SI_P-20 & 1080 & 425.0 & 3.6 & 50.0 & 923.8 & 5.8 & 88.8 & 3.3 & 18.2 & 3.4 \\
\hline Cast & Silicone (cond) & SI_GI-1120 & 1080 & 475.0 & 2.7 & 17.5 & 924.4 & 7.0 & 65.3 & 2.0 & 15.8 & 1.4 \\
\hline Cast & Silicone (cond) & SI_GI-1040 & 1100 & 225.0 & 3.6 & 35.0 & 930.3 & 14.7 & 82.0 & 40.2 & 14.4 & 2.8 \\
\hline Cast & Silicone (cond) & SI_GI-1000 & 1090 & 300.0 & 3.6 & 30.0 & 934.2 & 12.6 & 81.6 & 26.0 & 15.2 & 1.9 \\
\hline Cast & Silicone (add) & SI_P-10 & 1080 & 450.0 & 2.4 & 30.0 & 942.5 & 12.7 & 87.8 & 24.7 & 16.3 & 1.6 \\
\hline Cast & Silicone (add) & SI_P-15 & 1080 & 460.0 & 3.3 & 41.0 & 947.2 & 17.6 & 82.1 & 22.1 & 14.2 & 1.7 \\
\hline Cast & Silicone (add) & SO_DS_10 & 1070 & 1000.0 & 3.275 & 10.0 & 955.5 & 8.7 & 127.1 & 12.3 & 20.7 & 4.2 \\
\hline Cast & Silicone (cond) & SI_GI-1110T & 1080 & 450.0 & 1.89 & 12.0 & 959.9 & 6.0 & 86.4 & 3.0 & 21.7 & 1.1 \\
\hline Cast & Silicone (add) & SO_DS_FX_PRO & 1062 & 763.0 & 1.984 & 2.0 & 982.4 & 5.5 & 127.2 & 9.7 & 19.9 & 2.8 \\
\hline Cast & Silicone (add) & SO_EF-00-20 & 1070 & 845.0 & 1.102 & $20(00)$ & 986.2 & 4.9 & 136.9 & 11.3 & 21.9 & 2.1 \\
\hline Cast & Silicone (add) & SO_EF-00-35 & 1070 & 900.0 & 1.378 & $35(00)$ & 998.3 & 10.6 & 148.2 & 5.5 & 5.8 & 0.2 \\
\hline Cast & Silicone (add) & SI_P-44 & 1090 & 250.0 & 4.1 & 21.0 & NS & NS & NS & NS & 3.74 & 0.7 \\
\hline Print & FDM & ST ABS-M30 & 1040 & 7.0 & 32 & NS & NS & NS & NS & NS & 19.3 & 4.5 \\
\hline & $\begin{array}{l}\text { in (Sn) salt that ex } \\
\text { oridge between th } \\
\text { mple names are c } \\
\text { arbon, (CR) Carbc } \\
\text { untsman, (SI) Sili } \\
\text { long) elongation, } \\
\text { ere soft "skin-like } \\
\text { ardness scale. }\end{array}$ & $\begin{array}{l}\text { 1s water as a reactior } \\
\text { olymer chains. } \\
\text { ractions of the manu } \\
\text { Resin, (DS) DSM So } \\
\text { es, Inc., (SO) Smoo } \\
\text { S) tensile strength, (H } \\
\text { taterials that were m }\end{array}$ & $\begin{array}{l}\text { acturer an } \\
\text { nos, (ES) } \\
\text {-On, Inc., } \\
\text { ard) hardn } \\
\text { asured on }\end{array}$ & $\begin{array}{l}\text { the produ } \\
\text { OS, (FL) } \\
\text { ST) Strat } \\
\text { ss, (SA) } \\
\text { ne Shore ( }\end{array}$ & $\begin{array}{l}\text { t name fr } \\
\text { ormlabs, } \\
\text { sys. } \\
\text { tore A sc } \\
\text { o scale, w }\end{array}$ & $\begin{array}{l}n \text { the data } \\
\text { N) Proto } \\
\text { ich cover }\end{array}$ & $\begin{array}{l}\text { sheet: }(3 \\
\text { abs Fin } \\
\text { re } 00 \mathrm{sc} \\
\text { material }\end{array}$ & $\begin{array}{l}\text { 3D Sy } \\
\text { ine, (N1 } \\
\text { e. The ty } \\
\text { below th }\end{array}$ & $\begin{array}{l}\text { ems, (A } \\
\text { NinjaT } \\
\text { SO_E } \\
\text { range C }\end{array}$ & $\begin{array}{l}\text { ALM } \\
\text { (HN) } \\
00-\mathrm{XX} \\
\text { the Sho }\end{array}$ & A A & \\
\hline
\end{tabular}

Table A4. Material properties vs. $\mathrm{T}_{1}, \mathrm{~T}_{2}$, and $\mathrm{T}_{2}{ }^{*}$.

\begin{tabular}{llll}
\hline \hline Property & $\mathrm{T}_{1}$ & $\mathrm{~T}_{2}$ & $\mathrm{~T}_{2}{ }^{*}$ \\
\hline Density & No fit & No fit & No fit \\
\hline Elongation & No fit & $Y=22.57+0.1122 X$ & No fit \\
& & $R^{2}=0.523$ & \\
& & $p=0.0007$ & $Y=24.36-3.673 X$ \\
& $Y=1036-37.27 X$ & $Y=153.1-22.79 X$ & $R^{2}=0.430$ \\
& $R^{2}=0.593$ & $R^{2}=0.566$ & $p=0.003$ \\
\hline Tensile strength & $p=0.002$ & $p=0.0003$ & No fit \\
& No fit & No fit & \\
\hline
\end{tabular}




\section{Journal of Research of the National Institute of Standards and Technology}

\section{Appendix S}

\section{Supplementary Information}

Materials with no measurable signal using the described methods sorted by type, fabrication method and sample name.

Table S1.

\begin{tabular}{|c|c|c|c|c|c|c|c|c|}
\hline $\begin{array}{l}\text { Print/ } \\
\text { Cast } \\
\end{array}$ & Fabrication $^{\mathrm{a}}$ & Sample Name $^{\text {b }}$ & $\begin{array}{l}\text { Res } \\
(\mathbf{m m})^{\mathrm{c}} \\
\end{array}$ & $\begin{array}{r}\text { Density } \\
(\mathrm{kg} / \mathrm{m} 3) \\
\end{array}$ & $\begin{array}{c}\text { Elong } \\
(\%) \\
\end{array}$ & $\begin{array}{c}\text { TS } \\
\text { (Mpa) } \\
\end{array}$ & $\begin{array}{r}\text { Hard } \\
(\text { SA) } \\
\end{array}$ & $\begin{array}{l}\text { NS/ } \\
\text { NF } \\
\end{array}$ \\
\hline Cast & Polyurethane & HN_RP-6400 & ND & 1040 & 251.0 & 7.88 & 52 & NS \\
\hline Cast & Polyurethane & SO_FF-ITI6 & ND & 900 & ND & ND & ND & NS \\
\hline Cast & Polyurethane & SO_SMSH & ND & 1036 & 0.0 & ND & ND & NF \\
\hline Cast & Silicone (add) & SI_P-17 & ND & 1030 & 150.0 & 3.4 & 16.5 & $\mathrm{NF}$ \\
\hline Cast & Silicone (add) & SI_P-268 & ND & 1300 & 175.0 & 5.9 & ND & NS \\
\hline Cast & Silicone (add) & SI_P-50 & ND & 1300 & 200.0 & 5.2 & 44.5 & NS \\
\hline Cast & Silicone (add) & SI_P-60 & ND & 1240 & 200.0 & 6.2 & 53.0 & NS \\
\hline Cast & Silicone (add) & SO_SF15 & ND & 240 & ND & ND & ND & NS \\
\hline Cast & Silicone (cond) & SI_GI-311 & ND & 1140 & 150.0 & 2.2 & 43.0 & NS \\
\hline Cast & Silicone (cond) & SI GI-360 & ND & 1490 & 100.0 & 4.5 & 62.0 & NS \\
\hline Print & 3DP & 3D_CB_ZB & 0.150 & 1040 & 20.0 & ND & ND & NS \\
\hline Print & FDM & ST_ABS & 0.254 & 1080 & 6.0 & 33 & ND & NS \\
\hline Print & FDM & ST_ABS+P430_R & 0.254 & 1040 & 6.0 & 33 & ND & NS \\
\hline Print & FDM & ST_ABS+P430_U & 0.178 & ND & ND & ND & ND & NS \\
\hline Print & FDM & ST_ABS-ESD7 & 0.254 & 1040 & 3.0 & 36 & ND & NS \\
\hline Print & FDM & ST_ABSi & 0.254 & 1080 & 4.4 & 37 & ND & NS \\
\hline Print & FDM & ST_ABS-M30i & 0.254 & 1040 & 4.0 & 36 & ND & NS \\
\hline Print & FDM & ST_Ny_12_PA & 0.254 & 1160 & 30.0 & 46 & ND & NS \\
\hline Print & FDM & ST_PC & 0.254 & 1200 & 4.8 & 57 & ND & NS \\
\hline Print & FDM & ST_PC-ABS & 0.254 & 1098 & 5.0 & 34 & ND & NS \\
\hline Print & FDM & ST_PC-ISO & 0.254 & 1200 & 4.0 & 57 & ND & NS \\
\hline Print & FDM & ST UM 9085 & 0.254 & 1340 & 5.8 & 69 & NS & NS \\
\hline Print & PolyJet & ST_FLX2040 & 0.016 & 1120 & 110.0 & 1.3 & 37.5 & NS \\
\hline Print & PolyJet & ST_FLX2050 & 0.016 & 1120 & 95.0 & 1.9 & 47.5 & NS \\
\hline Print & PolyJet & ST_FLX2060 & 0.016 & 1120 & 75.0 & 2.5 & 60.0 & NS \\
\hline Print & PolyJet & ST_FLX2070 & 0.016 & 1120 & 65.0 & 3.5 & 70.0 & NS \\
\hline Print & PolyJet & ST_FLX2085 & 0.016 & 1120 & 55.0 & 5.5 & 82.5 & NS \\
\hline Print & PolyJet & ST_FLX2095 & 0.016 & 1120 & 40.0 & 9.8 & 95.0 & NS \\
\hline Print & PolyJet & ST_FLX930_P & 0.038 & 1120 & 170.0 & 0.79 & 27.0 & NS \\
\hline Print & PolyJet & ST_FLX930_U & 0.016 & 1120 & 170.0 & 0.8 & 27.0 & NS \\
\hline Print & PolyJet & ST_FLX9540 & 0.016 & 1120 & 100.0 & 1.3 & 40.0 & NS \\
\hline Print & PolyJet & ST_FLX9550 & 0.016 & 1120 & 80.0 & 2 & 53.5 & NS \\
\hline Print & PolyJet & ST_FLX9560 & 0.016 & 1120 & 60.0 & 2.8 & 63.5 & NS \\
\hline Print & PolyJet & ST_FLX9570 & 0.016 & 1120 & 50.0 & 3.8 & 74.0 & NS \\
\hline Print & PolyJet & ST_FLX9585 & 0.016 & 1120 & 35.0 & 6 & 86.0 & NS \\
\hline Print & PolyJet & ST_FLX9595 & 0.016 & 1120 & 27.0 & 9 & 95.5 & NS \\
\hline Print & PolyJet & ST_RGD5131DM & 0.038 & 1170 & 25.0 & 55 & ND & NS \\
\hline Print & PolyJet & ST_RGD5150 & 0.016 & ND & 18.0 & 45 & ND & NS \\
\hline
\end{tabular}


Journal of Research of the National Institute of Standards and Technology

\begin{tabular}{|c|c|c|c|c|c|c|c|c|}
\hline $\begin{array}{l}\text { Print/ } \\
\text { Cast } \\
\end{array}$ & Fabrication $^{\mathrm{a}}$ & Sample Name $^{\text {b }}$ & $\begin{array}{l}\text { Res } \\
(\mathbf{m m})^{\mathbf{c}} \\
\end{array}$ & $\begin{array}{r}\text { Density } \\
(\mathrm{kg} / \mathrm{m} 3) \\
\end{array}$ & $\begin{array}{c}\text { Elong } \\
(\%) \\
\end{array}$ & $\begin{array}{c}\text { TS } \\
\text { (Mpa) } \\
\end{array}$ & $\begin{array}{r}\text { Hard } \\
\text { (SA) } \\
\end{array}$ & $\begin{array}{l}\text { NS/ } \\
\text { NF } \\
\end{array}$ \\
\hline Print & PolyJet & ST_RGD525 & 0.016 & 1170 & 10.0 & 70 & ND & NS \\
\hline Print & PolyJet & ST_RGD810 & 0.038 & 1180 & 10.0 & 50 & ND & NS \\
\hline Print & PolyJet & ST_RGD835_PG & 0.016 & 1170 & 10.0 & 50 & NS & NS \\
\hline Print & PolyJet & ST_RGD835_SC & 0.038 & ND & ND & ND & NS & NS \\
\hline Print & PolyJet & ST_RGD8455 & 0.016 & ND & 20.0 & 35 & NS & NS \\
\hline Print & PolyJet & ST_RGD8460 & 0.016 & ND & 35.0 & 25 & NS & NS \\
\hline Print & Polyjet & ST RGD875 & 0.016 & 1170 & 10.0 & 50 & NS & NS \\
\hline Print & SLA & 3D_Acc_25 & 0.102 & 1190 & 13.0 & 38 & ND & NS \\
\hline Print & SLA & 3D_Acc_5530 & 0.051 & 1250 & 1.3 & 47 & ND & NS \\
\hline Print & SLA & 3D_Acc_60 & 0.051 & 1210 & 5.0 & 58 & ND & NS \\
\hline Print & SLA & 3D_Acc_XW200 & 0.102 & 1180 & 7.0 & 46 & ND & NS \\
\hline Print & SLA & CN_CE 220 & 0.150 & 1100 & 3.0 & 90 & ND & NS \\
\hline Print & SLA & CN_PR 25 & 0.150 & 1100 & 3.0 & 42 & ND & NS \\
\hline Print & SLA & CN_RPU 70 & 0.150 & 1010 & 90.0 & 42 & ND & NS \\
\hline Print & SLA & CR_EPU40 & 0.150 & 1000 & 190.0 & 6 & 68 & NS \\
\hline Print & SLA & DS_9120_PG & 0.051 & 1130 & 15.0 & 30 & ND & NS \\
\hline Print & SLA & DS_9120_PL & 0.051 & 1130 & 15.0 & 30 & ND & NS \\
\hline Print & SLA & DS_NanoT & 0.051 & 1650 & 0.7 & 66.3 & ND & NS \\
\hline Print & SLA & DS_NeXt & 0.102 & 1170 & 8.0 & 41 & ND & NS \\
\hline Print & SLA & DS_PG_18420 & 0.102 & 1160 & 12.0 & 42.7 & ND & NS \\
\hline Print & SLA & DS_Ws_XC_11122 & 0.102 & 1120 & 11.0 & 47 & ND & NS \\
\hline Print & SLA & FL_BLK & 0.025 & 1090 & 6.0 & 64.6 & ND & NS \\
\hline Print & SLA & FL_CAST & 0.025 & 1090 & 13.0 & 11.6 & ND & NS \\
\hline Print & SLA & FL_CLR & 0.025 & 1090 & 6.0 & 64.6 & ND & NS \\
\hline Print & SLA & FL_DENT & 0.050 & 1090 & ND & ND & ND & NS \\
\hline Print & SLA & FL_DENTM & 0.025 & ND & 5.0 & 61 & ND & NS \\
\hline Print & SLA & FL_DUR & 0.050 & ND & 67.0 & 31.8 & ND & NS \\
\hline Print & SLA & FL_FLEX & 0.050 & 1090 & 85.0 & 8.5 & 85 & NS \\
\hline Print & SLA & FL_GREY & 0.025 & 1090 & 6.0 & 64.6 & ND & NS \\
\hline Print & SLA & FL_HITMP & 0.025 & 1100 & 2.0 & 51 & ND & NS \\
\hline Print & SLA & FL_TOUGH & 0.050 & 1090 & 24.0 & 41.3 & ND & NS \\
\hline Print & SLA & FL_WHT & 0.050 & 1090 & 6.0 & 64.6 & ND & NS \\
\hline Print & SLA & FN_MF_G & 0.025 & 1170 & 6.1 & 44.9 & ND & NS \\
\hline Print & SLA & HN RS-7820 & .0.051 & 1130 & 8.0 & 35.8 & ND & NS \\
\hline Print & SLS & 3D_Duraf & 0.102 & 1200 & 4.5 & 31 & ND & NS \\
\hline Print & SLS & AL_PA_614GS & 0.102 & 1220 & 9.0 & 51 & ND & NS \\
\hline Print & SLS & AL_PA_650 & 0.102 & 1020 & 24.0 & ND & ND & NS \\
\hline Print & SLS & AL_PA_850 & 0.102 & 1030 & 51.0 & 48 & ND & NS \\
\hline Print & SLS & ES_PA_1102B & 0.150 & 990 & 45.0 & 48 & ND & NS \\
\hline Print & SLS & ES_PA_2200 & 0.060 & 900 & 20.0 & 45 & ND & NS \\
\hline Print & SLS & ST_VJ_PXL & 0.102 & 1000 & 0.2 & 14.2 & NS & NS \\
\hline
\end{tabular}

a (add) Addition cure, (SLS) Selective Laser Sintering, (SLA) Stereo Lithography Additive, (FDM) Fused Deposition Modeling, (3DP) 3D Printing.

b (3D) 3D Systems, (AL) ALM, (CN) Carbon, (CR) Carbon Resin, (DM) DSM Somos, (ES) EOS, (FL) Formlabs, (FN) Fineline Microfine Green, (HN) Huntsman, (SI) Silicones, Inc., (SO) Smooth-On, Inc., (ST) Stratasys.

${ }^{c}$ (ND) No data, (NS) No-Signal, (NF) No-Fit. 


\section{Statistical Analysis}

Note: The No-Data (ND) entries in Table S2 result in no plot labels for SI_P-44 on $\mathrm{T}_{1}$ and $\mathrm{T}_{2}$ plots, no SI_GI-300 on $\mathrm{T}_{2} *$ plots, and no SI_XP-565 for Elongation or Tensile Strength plots.

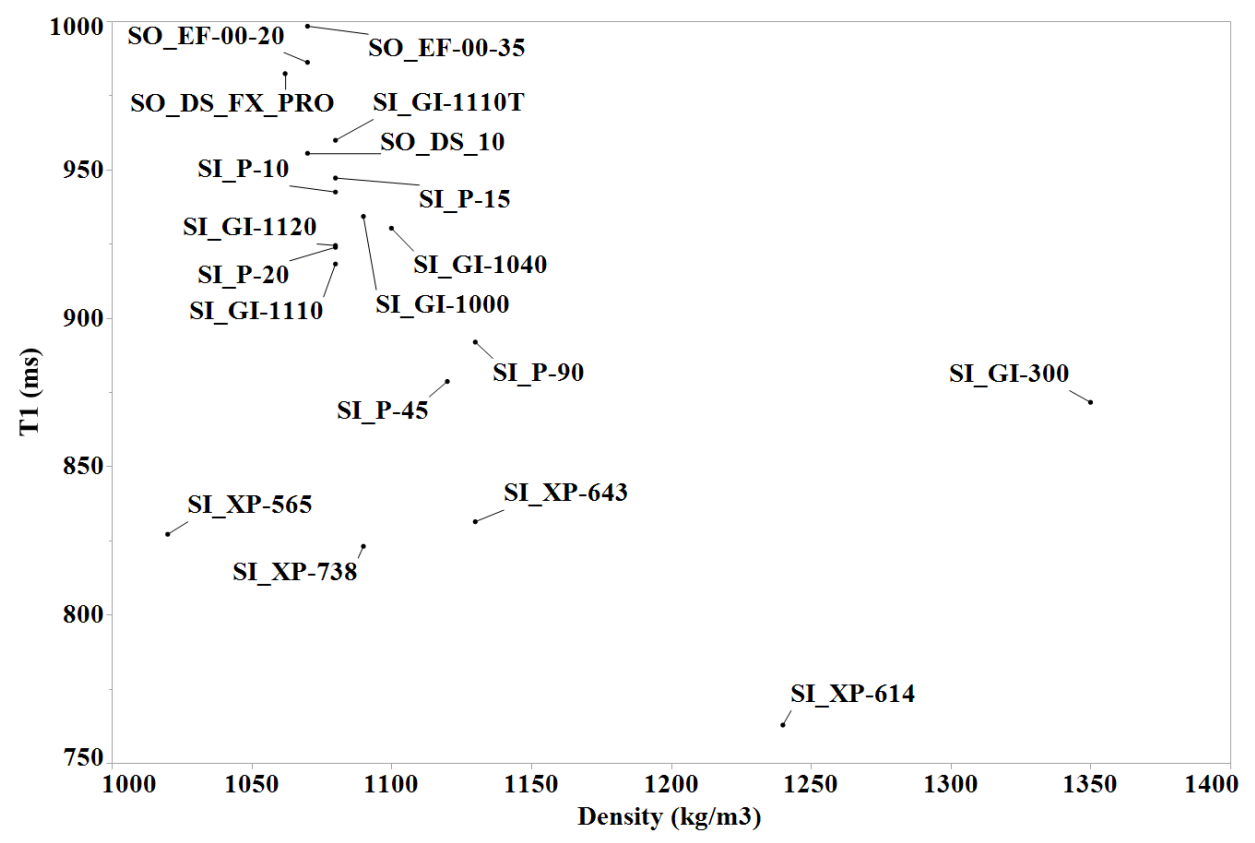

Fig. S1. $T_{1}$ vs Density.

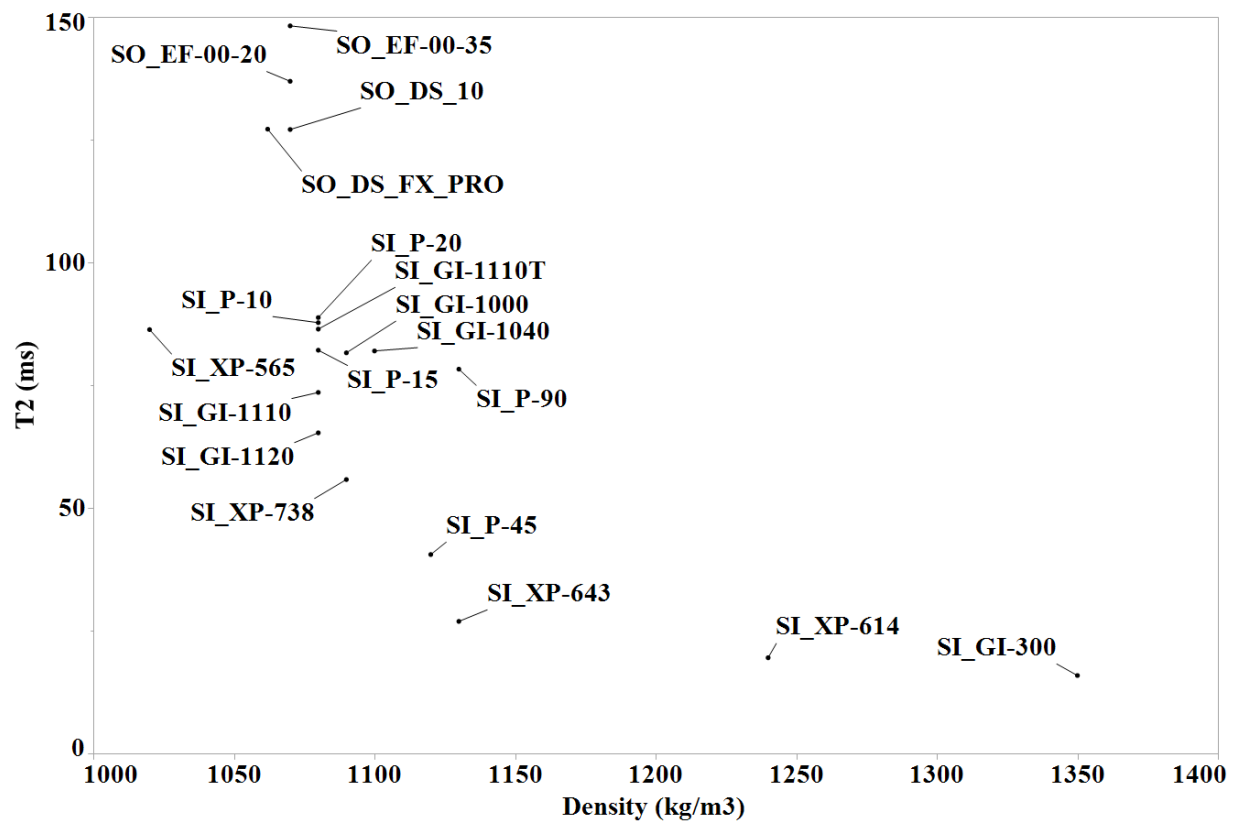

Fig. S2. $T_{2}$ vs Density. 
Journal of Research of the National Institute of Standards and Technology

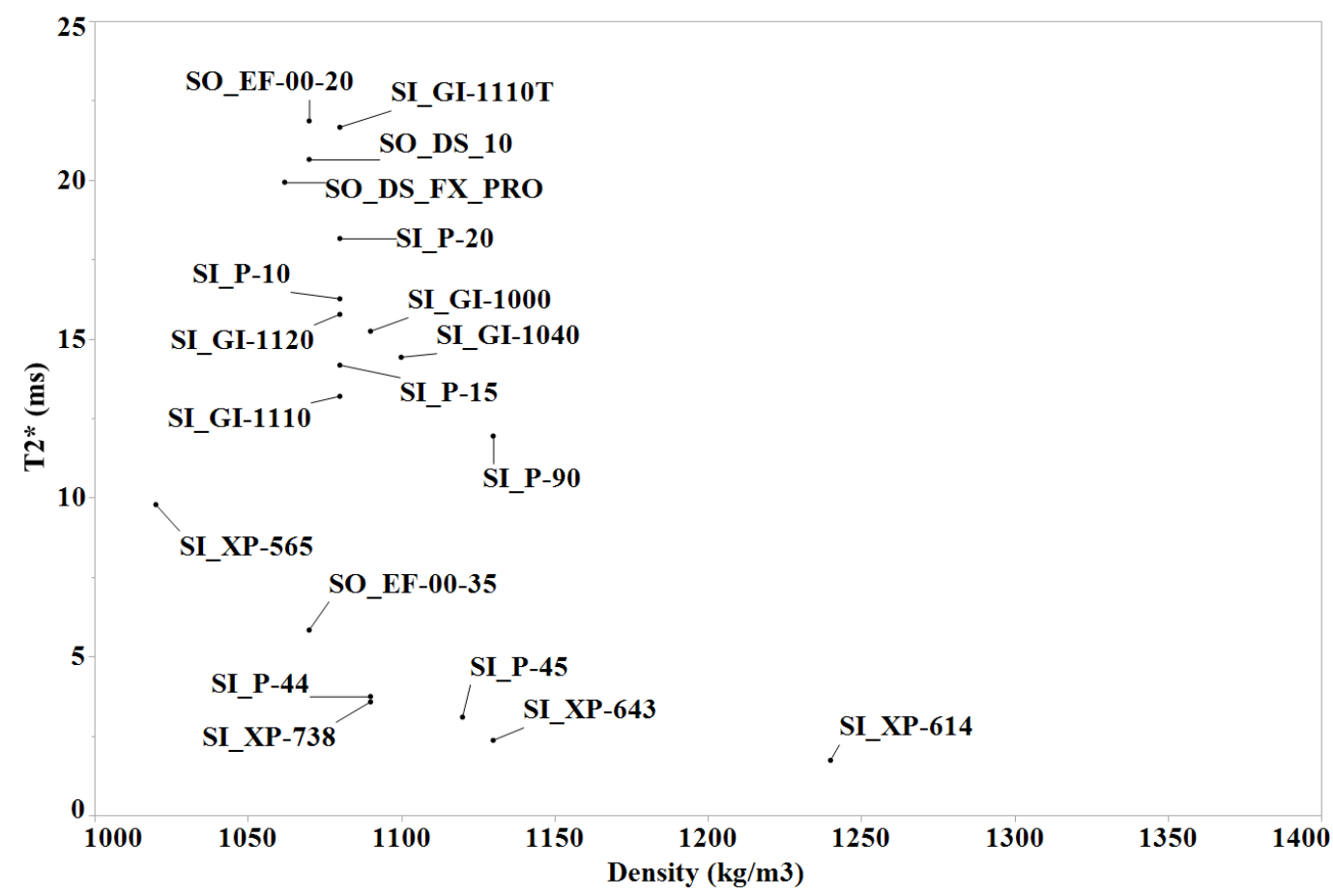

Fig. S3. $T_{2} *$ vs Density.

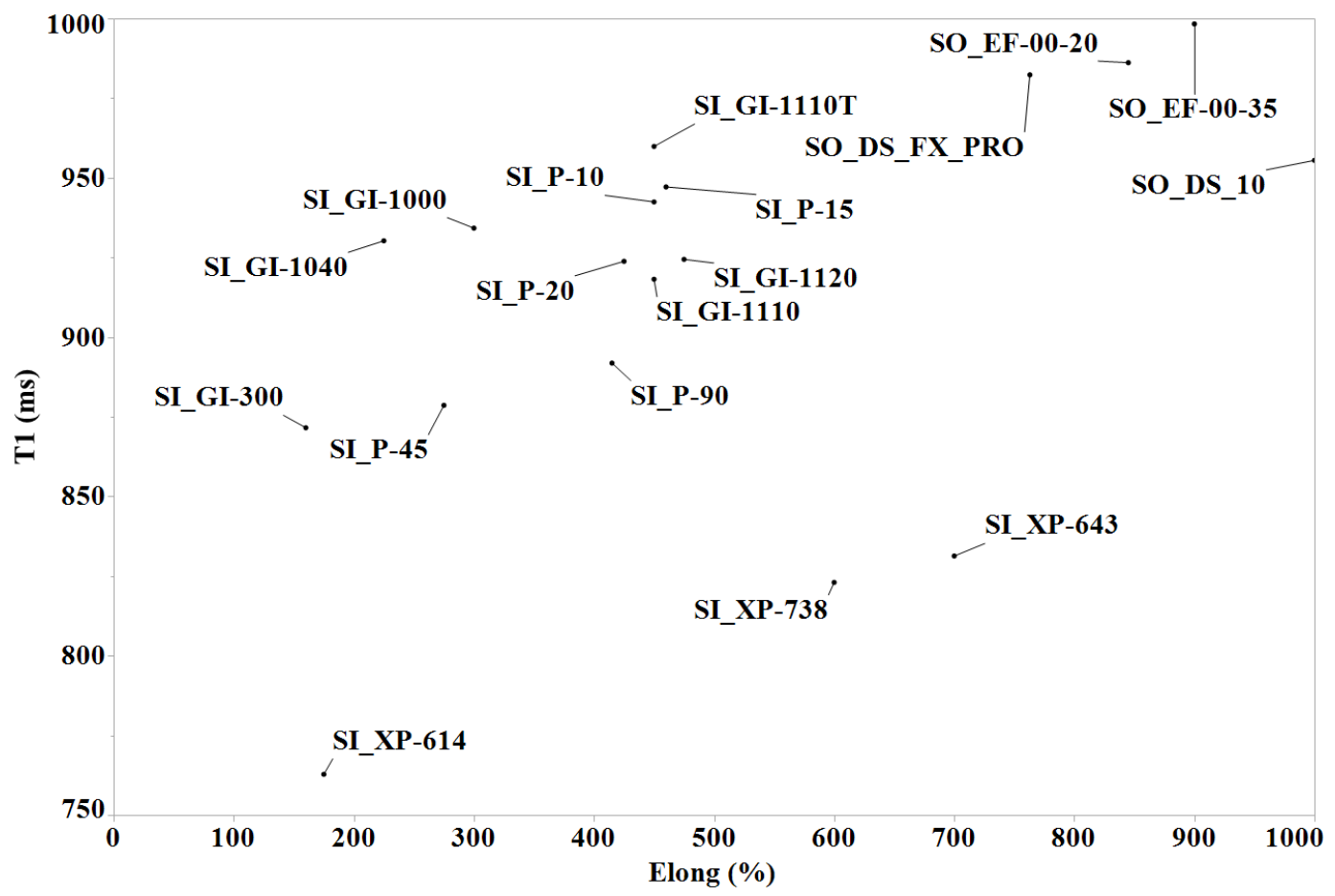

Fig. S4. $T_{1}$ vs Elongation. 


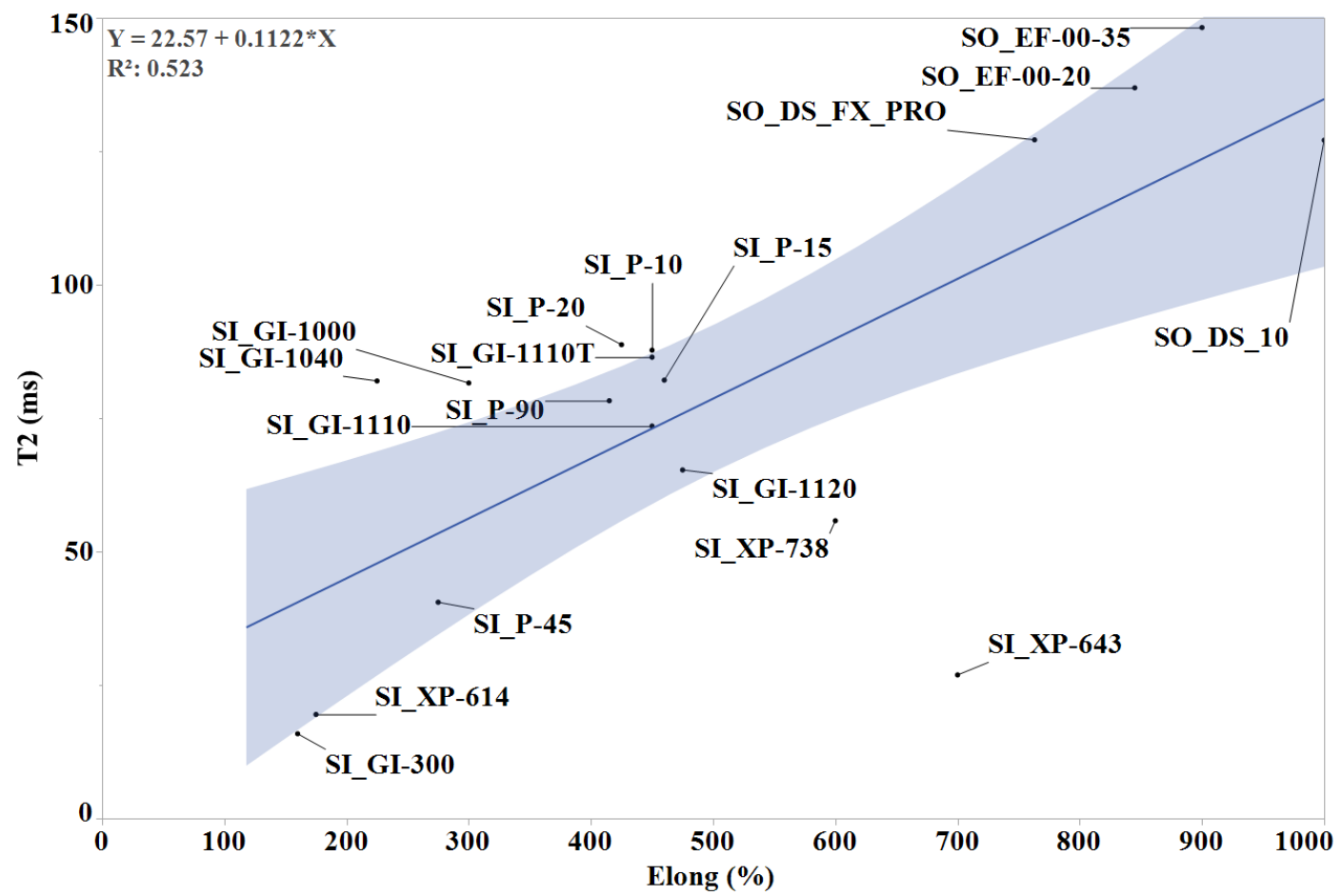

Fig. S5. $\mathrm{T}_{2}$ vs Elongation $-\mathrm{T}_{2}$ increases with increasing Elongation $(\mathrm{p}=0.0007)$.

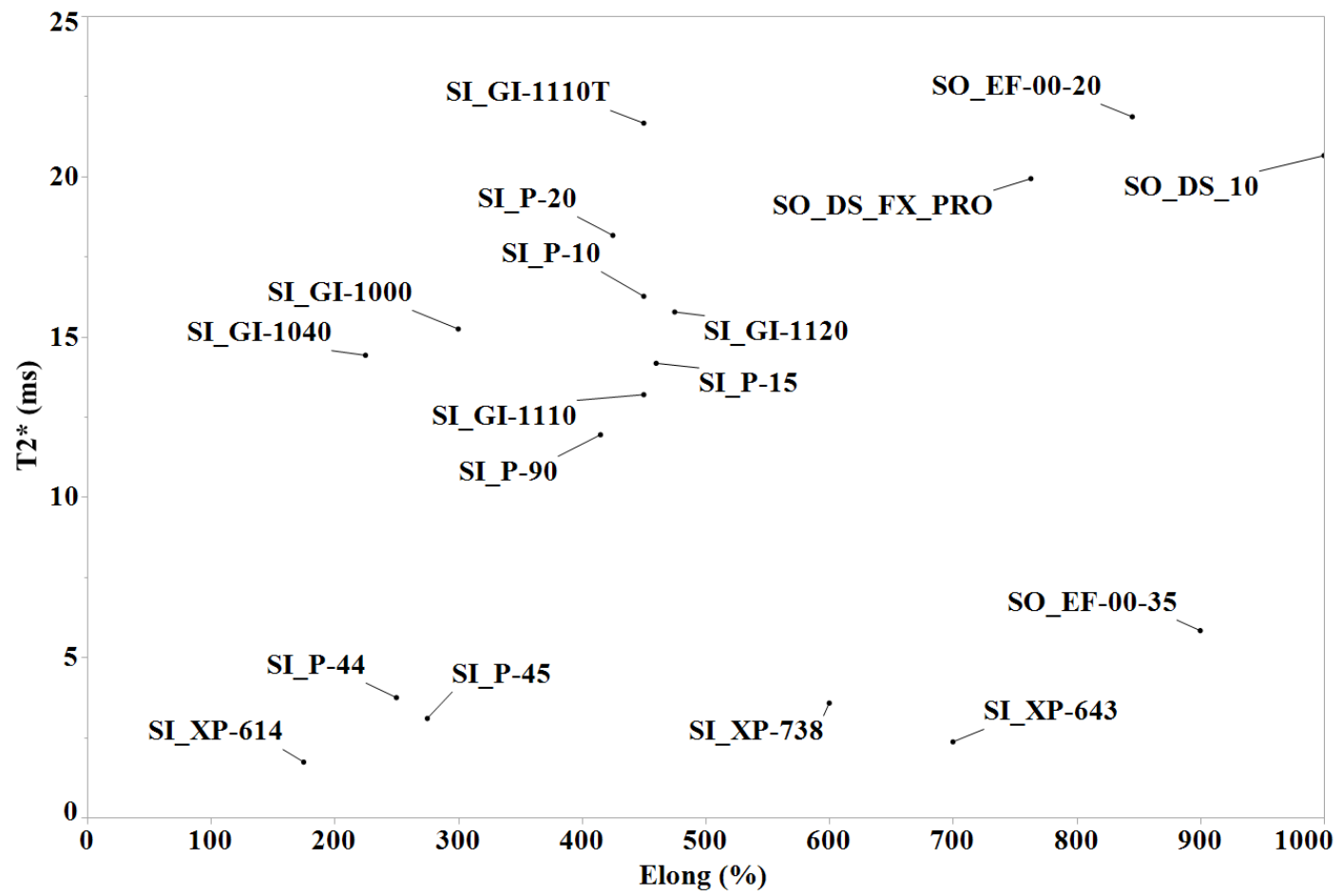

Fig. S6. $\mathrm{T}_{2} *$ vs Elongation. 


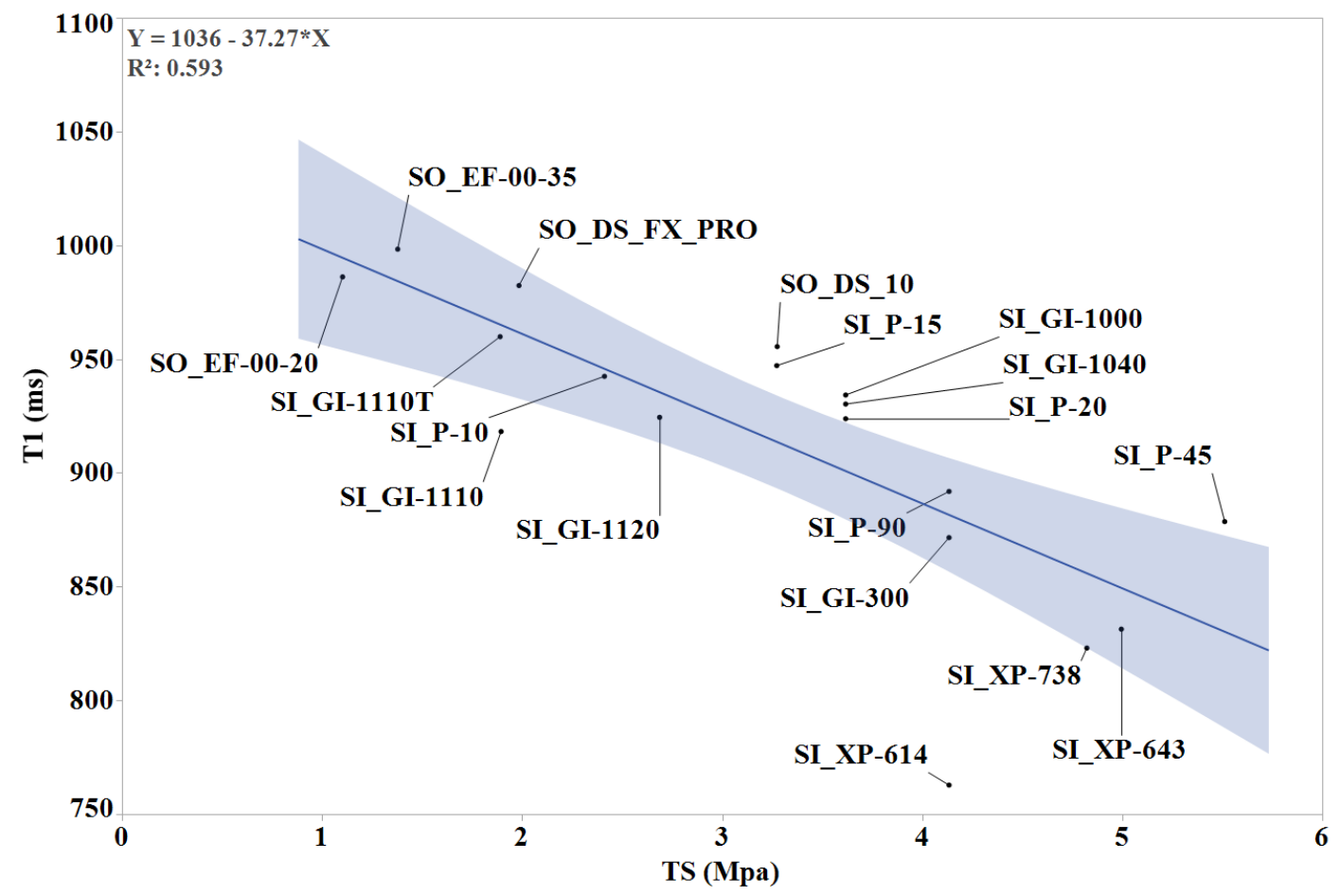

Fig. S7. $T_{1}$ vs Tensile Strength $-T_{1}$ decreases with increasing Tensile Strength $(p=0.002)$.

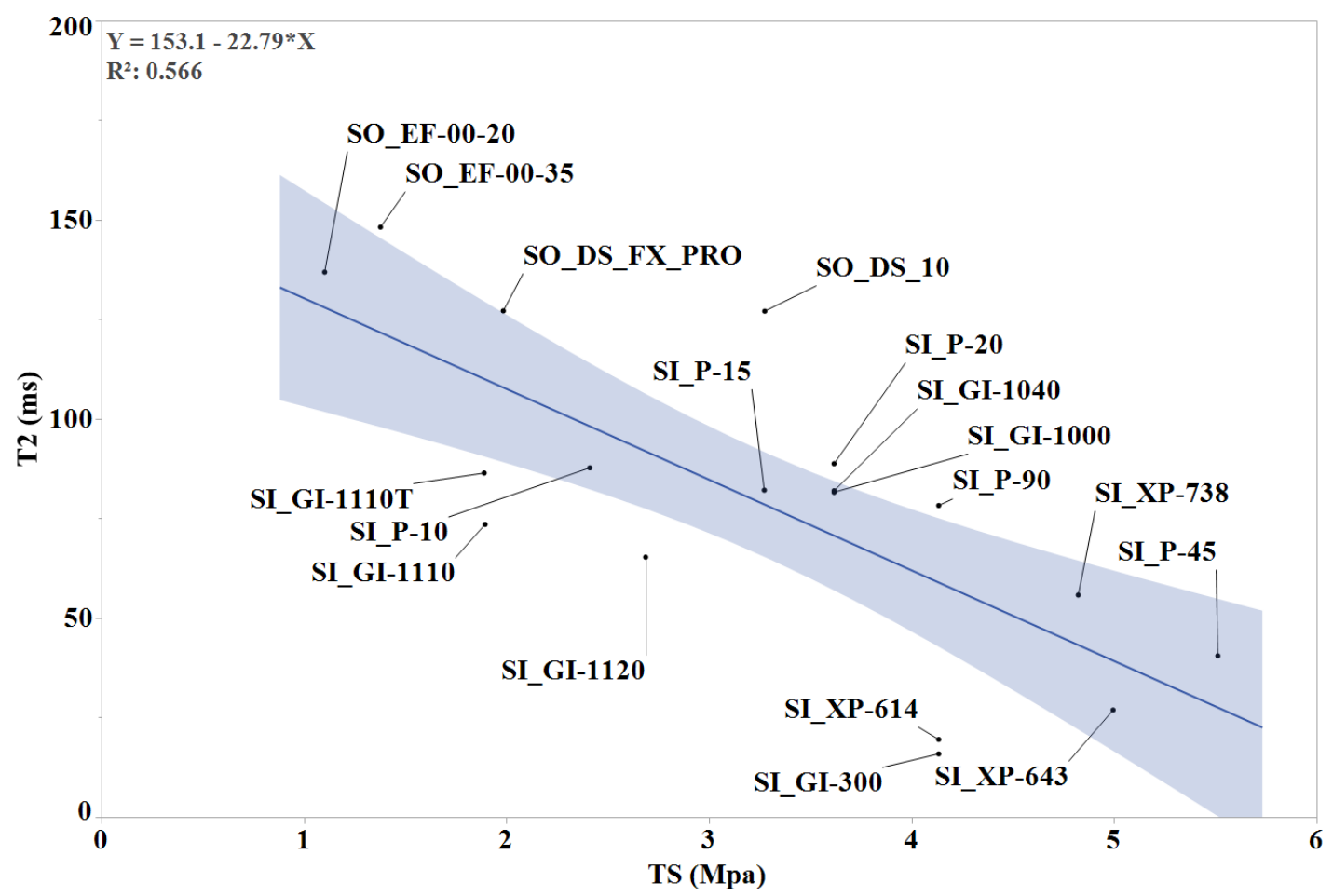

Fig. S8. $T_{2}$ vs Tensile Strength $-T_{2}$ decreases with increasing Tensile Strength $(p=0.0003)$. 


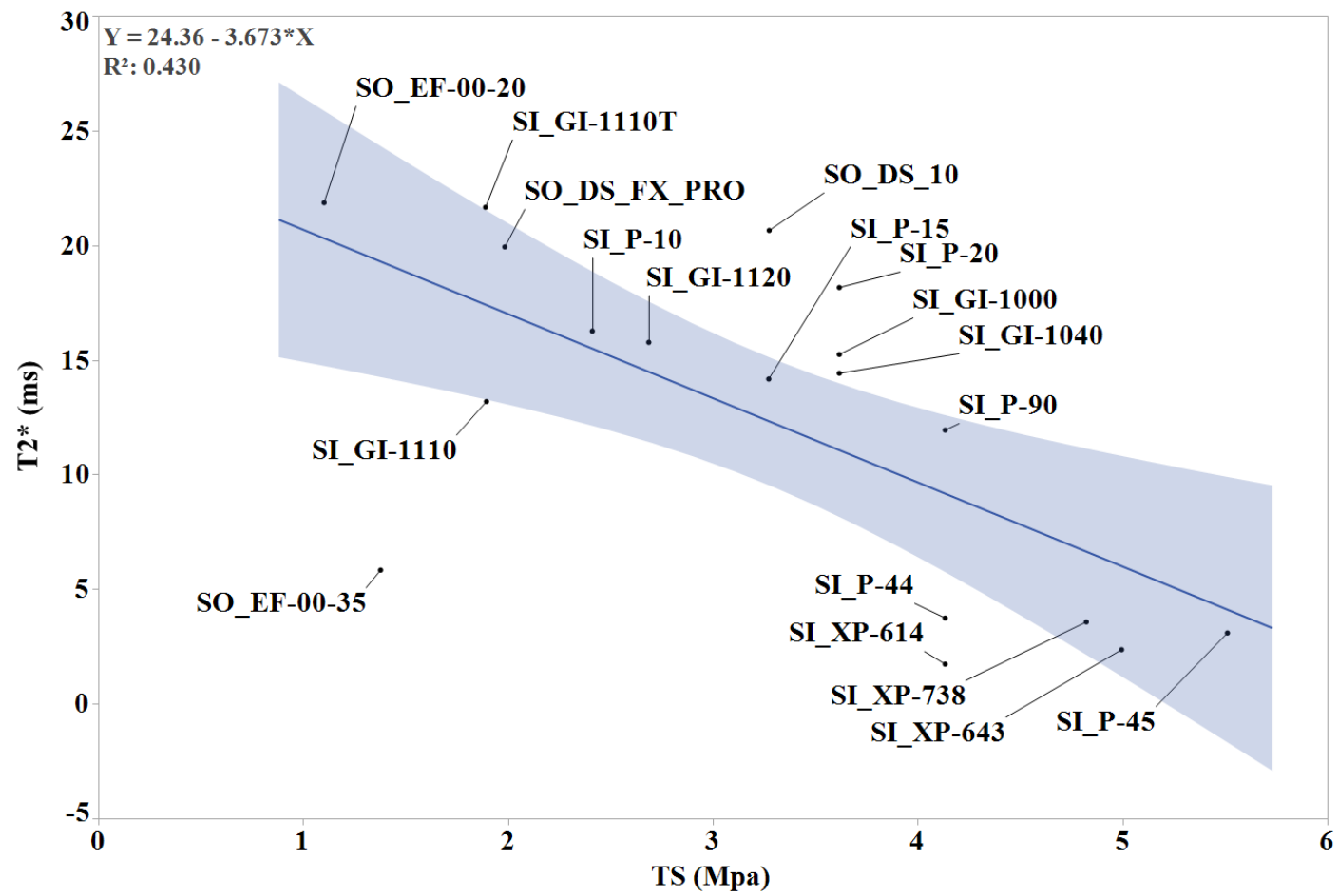

Fig. S9. $T_{2} *$ vs Tensile Strength $(p=0.0031)-T_{2} *$ decreases with increasing Tensile Strength and nearly meets the significance criteria.

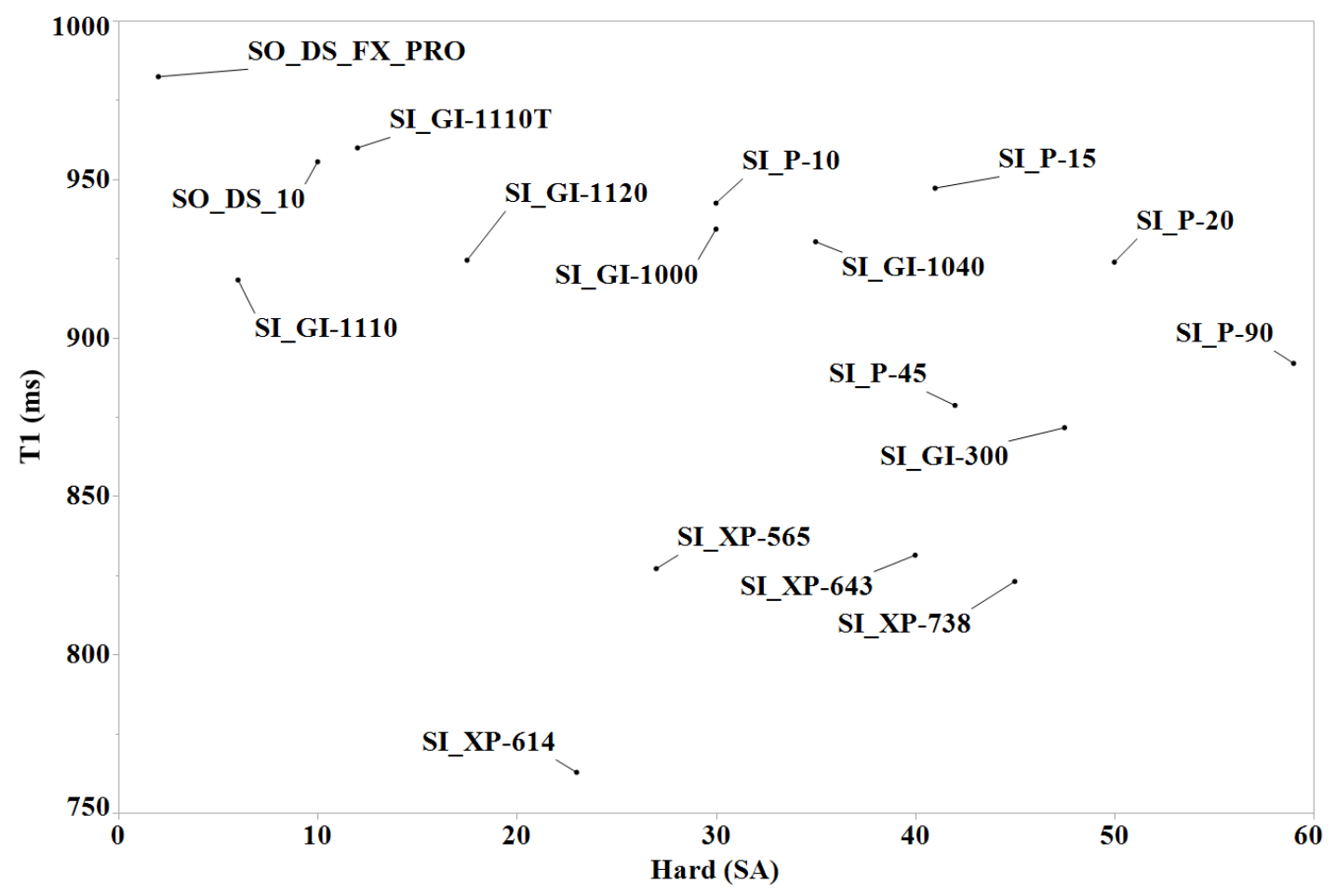

Fig. S10. T1 vs Hardness. 
Journal of Research of the National Institute of Standards and Technology

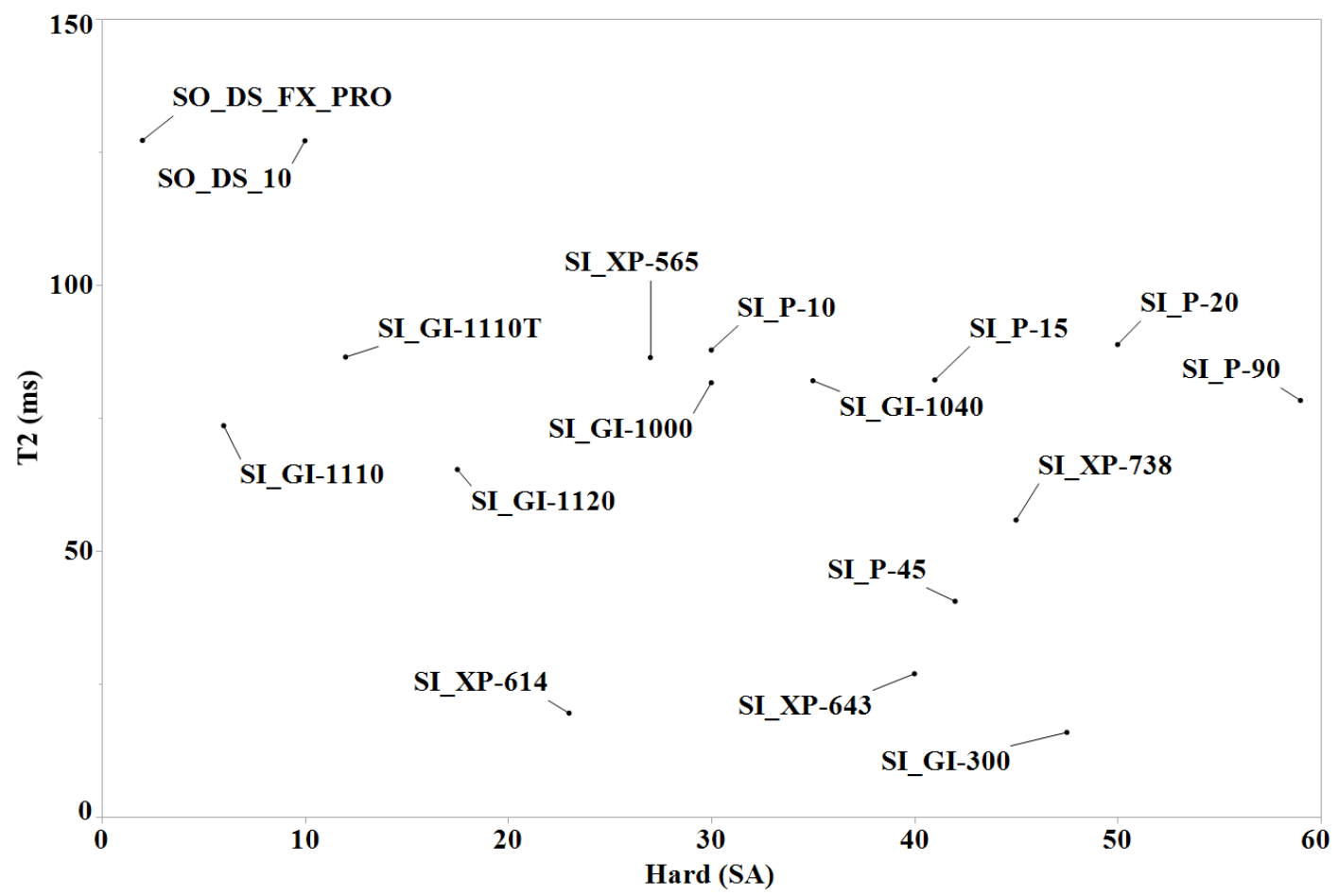

Fig. S11. $T_{2}$ vs Hardness.

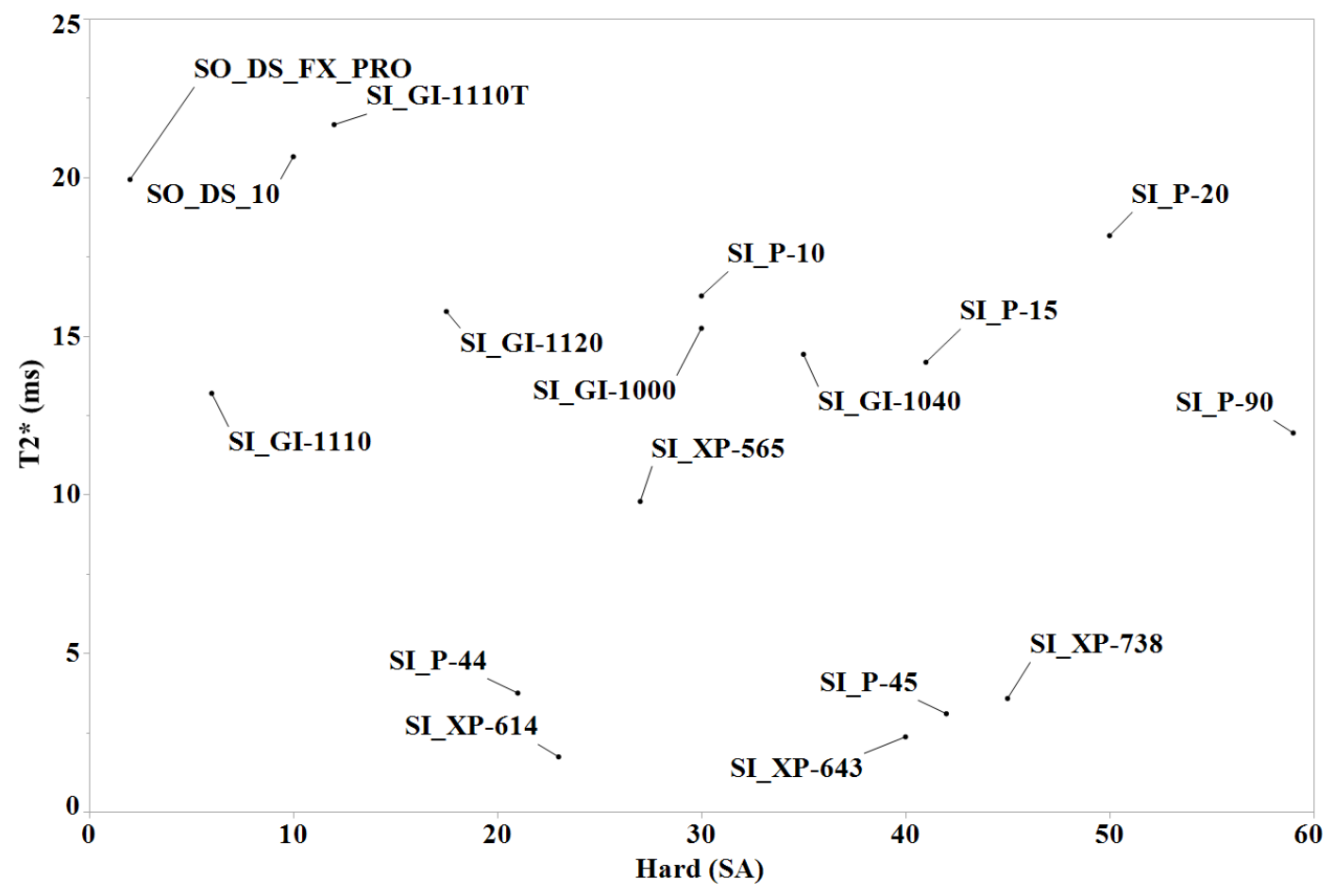

Fig. S12. $T_{2} *$ vs Hardness. 


\section{Acknowledgments}

This research was funded by a National Research Council (NRC) Research Associate Program (RAP) award to Bryan E. Yunker, Ph.D., at the NIST Boulder Laboratories

\section{References}

[1] Glick RP, Tiesi JA (1990) Subacute Pituitary Apoplexy: Clinical and Magnetic Resonance Imaging Characteristics. Neurosurgery 27(2):214-219. https://doi.org/10.1227/00006123-199008000-00007

[2] Kalfas I, Wilberger J, Goldberg A, Prostko ER (1988) Magnetic Resonance Imaging in Acute Spinal Cord Trauma. Neurosurgery 23(3):295-299. https://doi.org/10.1227/00006123-198809000-00002

[3] Pretorius PM , Quaghebeur G (2003) The Role of MRI in the Diagnosis of MS. Clinical Radiology 58(6):434-448. https://doi.org/https://doi.org/10.1016/S0009-9260(03)00089-8

[4] Wilberger JJE, Deeb Z, Rothfus W (1987) Magnetic Resonance Imaging in Cases of Severe Head Injury. Neurosurgery 20(4):571-576. https://doi.org/10.1227/00006123-198704000-00011

[5] Bushberg J (2012) The Essential Physics of Medical Imaging (Wolters Klewer).

[6] Keenan KE, Wilmes LJ, Aliu SO, Newitt DC, Jones EF, Boss MA, Stupic KF, Russek SE, Hylton NM (2016) Design of a breast phantom for quantitative MRI. Journal of Magnetic Resonance Imaging 44(3):610-619. https://doi.org/10.1002/jmri.25214

[7] Keenan KE, Ainslie M, Barker AJ, Boss MA, Cecil KM, Charles C, Chenevert TL, Clarke L, Evelhoch JL, Finn P, Gembris D, Gunter JL, Hill DLG, Jack CR, Jr., Jackson EF, Liu G, Russek SE, Sharma SD, Steckner M, Stupic KF, Trzasko JD, Yuan C, Zheng J (2018) Quantitative magnetic resonance imaging phantoms: A review and the need for a system phantom. Magnetic Resonance in Medicine 79(1):48-61. https://doi.org/10.1002/mrm.26982

[8] Al Jabbari O, Abu Saleh WK, Patel AP, Igo SR, Reardon MJ (2016) Use of three-dimensional models to assist in the resection of malignant cardiac tumors. Journal of Cardiac Surgery 31(9):581-583. https://doi.org/10.1111/jocs.12812

[9] Biglino G, Verschueren P, Zegels R, Taylor AM, Schievano S (2013) Rapid prototyping compliant arterial phantoms for in-vitro studies and device testing. Journal of Cardiovascular Magnetic Resonance 15:2. https://doi.org/10.1186/1532-429X-15-2

[10] Furdova A, Sramka M, Thurzo A, Furdova A (2017) Early experiences of planning stereotactic radiosurgery using 3D printed models of eyes with uveal melanomas. Clinical Ophthalmology (Auckland, NZ) 11:267-271. https://doi.org/10.2147/OPTH.S123640

[11] Gear JI, Cummings C, Craig AJ, Divoli A, Long CD, Tapner M, Flux GD (2016) Abdo-Man: a 3D-printed anthropomorphic phantom for validating quantitative SIRT. EJNMMI Phys 3(1):17. https://doi.org/10.1186/s40658-016-0151-6

[12] Lan Q, Chen A, Zhang T, Li G, Zhu Q, Fan X, Ma C, Xu T (2016) Development of Three-Dimensional Printed Craniocerebral Models for Simulated Neurosurgery. World Neurosurgery 91:434-442. https://doi.org/10.1016/j.wneu.2016.04.069

[13] Lioufas PA, Quayle MR, Leong JC, McMenamin PG (2016) 3D Printed Models of Cleft Palate Pathology for Surgical Education. Plastic and Reconstructive Surgery - Global Open 4(9):e1029. https://doi.org/10.1097/GOX.0000000000001029

[14] Liu P, Liu R, Zhang Y, Liu Y, Tang X, Cheng Y (2016) The Value of 3D Printing Models of Left Atrial Appendage Using RealTime 3D Transesophageal Echocardiographic Data in Left Atrial Appendage Occlusion: Applications toward an Era of Truly Personalized Medicine. Cardiology 135(4):255-261. https://doi.org/10.1159/000447444

[15] Nikolaou P, Coffey AM, Walkup LL, Gust BM, LaPierre CD, Koehnemann E, Barlow MJ, Rosen MS, Goodson BM, Chekmenev EY (2014) A 3D-printed high power nuclear spin polarizer. Journal of the American Chemical Society 136(4):16361642. https://doi.org/10.1021/ja412093d

[16] Radenkovic D, Solouk A, Seifalian A (2016) Personalized development of human organs using 3D printing technology. Medical Hypotheses 87:30-33. https://doi.org/10.1016/j.mehy.2015.12.017

[17] Ryan JR, Chen T, Nakaji P, Frakes DH, Gonzalez LF (2015) Ventriculostomy Simulation Using Patient-Specific Ventricular Anatomy, 3D Printing, and Hydrogel Casting. World Neurosurgery 84(5):1333-1339. https://doi.org/10.1016/j.wneu.2015.06.016

[18] Zhao W, Shen C, Cai R, Wu J, Zhuang Y, Cai Z, Wang R, Chen C (2017) Minimally invasive surgery for resection of ossification of the ligamentum flavum in the thoracic spine. Wideochir Inne Tech Maloinwazyjne 12(1):96-105. https://doi.org/10.5114/wiitm.2017.66473

[19] Herrmann KH, Gartner C, Gullmar D, Kramer M, Reichenbach JR (2014) 3D printing of MRI compatible components: why every MRI research group should have a low-budget 3D printer. Medical Engineering and Physics 36(10):1373-1380. https://doi.org/10.1016/j.medengphy.2014.06.008

[20] Mano I, Goshima H, Nambu M, Iio M (1986) New polyvinyl alcohol gel material for MRI phantoms. Magnetic Resonance in Medicine 3(6):921-926.

[21] Mitsouras D, Lee TC, Liacouras P, Ionita CN, Pietilla T, Maier SE, Mulkern RV (2017) Three-dimensional printing of MRIvisible phantoms and MR image-guided therapy simulation. Magnetic Resonance in Medicine 77(2):613-622. https://doi.org/10.1002/mrm.26136

[22] Yunker BE, Cordes D, Scherzinger AL, Dodd GD, Shandas R, Feng Y, Hunter KS (2013) An investigation of industrial molding compounds for use in 3D ultrasound, MRI, and CT imaging phantoms. Medical Physics 40(5):052905. https://doi.org/10.1118/1.4802083 
[23] Yunker BE, Dodd GD, Chen SJ, Chang S, Lanning CJ, Scherzinger AL, Shandas R, Feng Y, Hunter KS (2014) The design and fabrication of two portal vein flow phantoms by different methods. Medical Physics 41(2):023701. https://doi.org/10.1118/1.4861819

[24] Russek SE, Stupic KF, Biller JR, Boss MA, Keenan KE, Mirowski E (2020) Electromagnetics for Quantitative Magnetic Resonance Imaging. Compendium on Electromagnetic Analysis, (World Scientific), pp 95-147.

[25] Clique H, Cheng H-LM, Marie P-Y, Felblinger J, Beaumont M (2014) 3D myocardial T1 mapping at 3T using variable flip angle method: Pilot study. Magnetic Resonance in Medicine 71(2):823-829. https://doi.org/10.1002/mrm.24688

[26] Preibisch C , Deichmann R (2009) Influence of RF spoiling on the stability and accuracy of T1 mapping based on spoiled FLASH with varying flip angles. Magnetic Resonance in Medicine 61(1):125-135. https://doi.org/10.1002/mrm.21776

[27] Du J, Carl M, Bydder M, Takahashi A, Chung CB, Bydder GM (2010) Qualitative and quantitative ultrashort echo time (UTE) imaging of cortical bone. Journal of Magnetic Resonance 207(2):304-311. https://doi.org/10.1016/j.jmr.2010.09.013

[28] Rakow-Penner R, Daniel B, Yu H, Sawyer-Glover A, Glover GH (2006) Relaxation times of breast tissue at 1.5T and 3T measured using IDEAL. Journal of Magnetic Resonance Imaging 23(1):87-91. https://doi.org/10.1002/jmri.20469

[29] Bae WC, Chen PC, Chung CB, Masuda K, D'Lima D, Du J (2012) Quantitative ultrashort echo time (UTE) MRI of human cortical bone: correlation with porosity and biomechanical properties. Journal of Bone and Mineral Research 27(4):848-857. https://doi.org/10.1002/jbmr.1535

[30] Han E, Gold G, Stainsby J, Wright G, Beaulieu C, Brittain J (2003) In-Vivo T1 and T2 Measurements of Muskuloskeletal Tissue at $3 \mathrm{~T}$ and 1.5T. Proc ISMRM 11 .

[31] Edden RAE, Smith SA, Barker PB (2010) Longitudinal and multi-echo transverse relaxation times of normal breast tissue at 3 Tesla. Journal of Magnetic Resonance Imaging 32(4):982-987. https://doi.org/10.1002/jmri.22306

[32] deBazelaire CMJ, Duhamel GD, Rofsky NM, Alsop DC (2004) MR Imaging Relaxation Times of Abdominal and Pelvic Tissues Measured in Vivo at 3.0 T: Preliminary Results. Radiology 230(3):652-659. https://doi.org/10.1148/radiol.2303021331

[33] Bojorquez JZ, Bricq S, Acquitter C, Brunotte F, Walker PM, Lalande A (2017) What are normal relaxation times of tissues at 3 T? Magnetic Resonance Imaging 35(Supplement C):69-80. https://doi.org/https://doi.org/10.1016/j.mri.2016.08.021

[34] Sheth V, Shao H, Chen J, Vandenberg S, Corey-Bloom J, Bydder GM, Du J (2016) Magnetic resonance imaging of myelin using ultrashort Echo time (UTE) pulse sequences: Phantom, specimen, volunteer and multiple sclerosis patient studies. Neuroimage 136:37-44. https://doi.org/10.1016/j.neuroimage.2016.05.012

[35] Lu H, Nagae-Poetscher LM, Golay X, Lin D, Pomper M, van Zijl PCM (2005) Routine clinical brain MRI sequences for use at 3.0 Tesla. Journal of Magnetic Resonance Imaging 22(1):13-22. https://doi.org/10.1002/jmri.20356

[36] Barral JK, Gudmundson E, Stikov N, Etezadi-Amoli M, Stoica P, Nishimura DG (2010) A robust methodology for in vivo T1 mapping. Magnetic Resonance in Medicine 64(4):1057-1067. https://doi.org/10.1002/mrm.22497

[37] Pai A, Li X, Majumdar S (2008) A comparative study at $3 \mathrm{~T}$ of sequence dependence of T2 quantitation in the knee. Magnetic Resonance Imaging 26(9):1215-1220. https://doi.org/https://doi.org/10.1016/j.mri.2008.02.017

[38] Chen Y, Jiang Y, Pahwa S, Ma D, Lu L, Twieg MD, Wright KL, Seiberlich N, Griswold MA, Gulani V (2016) MR Fingerprinting for Rapid Quantitative Abdominal Imaging. Radiology 279(1):278-286. https://doi.org/10.1148/radiol.2016152037

[39] Jiang Y, Ma D, Seiberlich N, Gulani V, Griswold MA (2015) MR fingerprinting using fast imaging with steady state precession (FISP) with spiral readout. Magnetic Resonance in Medicine 74(6):1621-1631. https://doi.org/10.1002/mrm.25559

[40] deRoquefeuil M, Vuissoz PA, Escanye JM, Felblinger J (2013) Effect of physiological heart rate variability on quantitative T2 measurement with ECG-gated Fast Spin Echo (FSE) sequence and its retrospective correction. Magnetic Resonance Imaging 31(9):1559-1566. https://doi.org/10.1016/j.mri.2013.06.006

[41] vanHeeswijk RB, Feliciano H, Bongard C, Bonanno G, Coppo S, Lauriers N, Locca D, Schwitter J, Stuber M (2012) Freebreathing 3 T magnetic resonance T2-mapping of the heart. JACC: Cardiovascular Imaging 5(12):1231-1239. https://doi.org/10.1016/j.jcmg.2012.06.010

[42] Stanisz GJ OE, Pun J, Escaravage M, Graham SJ, Bronskill MJ, Henkelman RM (2005) T1, T2 relaxation and magnetization transfer in tissue at 3T. MRM 54(3):507-512

[43] Fennessy FM, Fedorov A, Gupta SN, Schmidt EJ, Tempany CM, Mulkern RV (2012) Practical considerations in T1 mapping of prostate for dynamic contrast enhancement pharmacokinetic analyses. Magnetic Resonance Imaging 30(9):1224-1233. https://doi.org/https://doi.org/10.1016/j.mri.2012.06.011

\footnotetext{
About the authors: Bryan Yunker is a former National Research Council fellow in the Magnetic Measurement Group of NIST in Boulder, Colorado. Dr. Yunker's research interests include the reconstruction of patient anatomy from 3D CT/MRI/ultrasound data, computational fluid dynamics, and parallel computing. Dr. Yunker holds a Ph.D. in bioengineering from the University of ColoradoDenver/Anschutz, a certificate in engineering management from University of Colorado-Boulder, and a bachelor of science in electrical engineering from Washington State University.

Karl Stupic is a chemist in the Physical Measurement Laboratory at NIST. He has worked on SItraceable phantoms and leads a project to develop low-field magnetic resonance imaging (MRI), novel MRI for agricultural and environmental metrology, and hyperpolarized MRI.
} 


\section{Journal of Research of the National Institute of Standards and Technology}

Jennifer Wagner is an instructor in the Department of Bioengineering and the University of Colorado School of Medicine Center for Bioengineering at the University of Colorado-Denver/Anschutz.

Stephen Huddle is a professional research assistant in the Biomechatronics Development Laboratory in the Department of Bioengineering at the University of Colorado-Denver/Anschutz in Aurora, CO. Stephen specializes in the $3 D$ printing of plastic and metal parts for limb replacement research.

Robin Shandas is a CU Distinguished Professor and founding Chair of the Department of Bioengineering at the University of Colorado-Denver/Anschutz. Professor Shandas' areas of research include cardiovascular biomechanics, imaging, medical device design, translational biomedical engineering, new materials, and $3 D$ bioprinting.

Richard Weir is a research associate professor and principal investigator of the Biomechatronics Development Laboratory in the Department of Bioengineering at the University of ColoradoDenver/Anschutz. Professor Weir is developing better prosthetic limb systems by conducting research in fields ranging from $3 D$ metal printing to optogenetics.

Stephen Russek is a physicist in the Physical Measurement Laboratory at NIST. He heads the Imaging Physics Project and has developed and commercialized several medical imaging phantoms. He is currently working on three-dimensional printing of biomimetic phantoms, extending traceable measurements into the human body, and developing micro-MRI systems.

Kathryn Keenan is a bioengineer in the Physical Measurement Laboratory at NIST and leads the Quantitative MRI Project. She has developed and commercialized an MRI breast phantom and is developing new techniques for in-vivo thermometry using MR fingerprinting.

The National Institute of Standards and Technology is an agency of the U.S. Department of Commerce. 